OPEN ACCESS

Edited by:

Emmanuel Donnadieu,

Institut National de la Santé et de la

Recherche Médicale (INSERM),

France

Reviewed by:

Ishak Ozel Tekin,

Bülent Ecevit University, Turkey

Gordon A. Francis,

University of British Columbia, Canada

${ }^{*}$ Correspondence:

Lukas Tomas

lukas.tomas@med.uni-muenchen.de

${ }^{\dagger}$ These authors have contributed equally to this work and share first authorship

Specialty section:

This article was submitted to Molecular Innate Immunity,

a section of the journal

Frontiers in Immunology

Received: 31 May 2021

Accepted: 30 September 2021

Published: 25 October 2021

Citation:

Tomas L, Prica F and Schulz C (2021) Trafficking of Mononuclear

Phagocytes in Healthy Arteries and Atherosclerosis.

Front. Immunol. 12:718432. doi: 10.3389/fimmu.2021.718432

\section{Trafficking of Mononuclear Phagocytes in Healthy Arteries and Atherosclerosis}

\author{
Lukas Tomas $^{1,2 *}$, Filip Prica ${ }^{1,2 \dagger}$ and Christian Schulz ${ }^{1,2}$ \\ ${ }^{1}$ Department of Medicine I, University Hospital, Ludwig Maximilian University, Munich, Germany, ${ }^{2}$ DZHK (German Centre for \\ Cardiovascular Research), Partner Site Munich Heart Alliance, Munich, Germany
}

Monocytes and macrophages play essential roles in all stages of atherosclerosis - from early precursor lesions to advanced stages of the disease. Intima-resident macrophages are among the first cells to be confronted with the influx and retention of apolipoprotein Bcontaining lipoproteins at the onset of hypercholesterolemia and atherosclerosis development. In this review, we outline the trafficking of monocytes and macrophages in and out of the healthy aorta, as well as the adaptation of their migratory behaviour during hypercholesterolemia. Furthermore, we discuss the functional and ontogenetic composition of the aortic pool of mononuclear phagocytes and its link to the atherosclerotic disease process. The development of mouse models of atherosclerosis regression in recent years, has enabled scientists to investigate the behaviour of monocytes and macrophages during the resolution of atherosclerosis. Herein, we describe the dynamics of these mononuclear phagocytes upon cessation of hypercholesterolemia and how they contribute to the restoration of tissue homeostasis. The aim of this review is to provide an insight into the trafficking, fate and disease-relevant dynamics of monocytes and macrophages during atherosclerosis, and to highlight remaining questions. We focus on the results of rodent studies, as analysis of cellular fates requires experimental manipulations that cannot be performed in humans but point out findings that could be replicated in human tissues. Understanding of the biology of macrophages in atherosclerosis provides an important basis for the development of therapeutic strategies to limit lesion formation and promote plaque regression.

Keywords: atherosclerosis, macrophage, monocyte, regression, trafficking

\section{INTRODUCTION}

Atherosclerosis is characterised by a chronic, low-grade inflammation in the arterial wall. As the underlying pathology for myocardial infarction and stroke, it is the leading cause of death worldwide (1). The inflammatory response in the arterial wall is initiated by the hypercholesterolemia-induced subendothelial retention of apolipoprotein (apo)B-containing lipoproteins, mainly low-density lipoprotein (LDL), at sites of non-laminar and low shear stress blood flow. These sites are characterised by a higher abundance of macrophages (2-4), 
inflammation-primed endothelial cells (5) and particularly in humans a pro-retentive thickened intima rich in smooth muscle cells and altered extracellular matrix (6-8). The subendothelial retention makes the lipoproteins susceptible to enzymatic and non-enzymatic modification. In particular, oxidation of LDL triggers a sterile inflammatory reaction by activating the endothelial cells to upregulate adhesion molecules and secrete chemokines which attract monocytes and other leukocytes. Modification of lipoproteins also promotes their uptake by macrophages and vascular smooth muscle cells (VSMC) leading to the appearance of foam cells. Additionally, oxidized LDL contains several bioactive molecules, including oxidized phospholipids, which act as damage-associated molecular patterns (DAMPs), and together with early cholesterol crystal formation cause an activation of surrounding innate immune cells $(9,10)$. The continuous influx, retention and modification of apoB-containing lipoproteins, together with the defective resolution of inflammation and dysfunctional clearance of dead cells (efferocytosis) fuel the chronic inflammation (11). The persistent inflammatory activity also leads to the generation of autoantigens and involvement of the adaptive immune system at later stages of the disease $(12,13)$.

Resident arterial macrophages play a crucial role in tissue homeostasis and serve as immune sentinels within the tissue. Adventitial macrophages, for instance, are important regulators of collagen production and the arterial tone (14). At areas of low blood velocity and shear stress, macrophages beneath the endothelium survey the environment to detect pathogens or potentially hazardous deposits (15). As such, aortic intimaresident macrophages are among the first cells to encounter trapped apoB-containing lipoproteins at the initiation of hypercholesterolemia (2-4). Mainly based on their expression of CD11c, these subendothelial phagocytes were initially described as dendritic cells, but recent results have challenged this view and have identified macrophages as the main cell type to first encounter the trapped lipids (16). Furthermore, in mice with a deficiency of monocytes and macrophages, a delayed and almost abolished development of atherosclerotic plaques can be seen (17-21). This further underlines the importance of the monocyte-macrophage axis in the initiation of atherosclerotic disease. With the development of mouse models for atherosclerotic regression, it has become clear that macrophages are not only important drivers of the disease, but their plasticity and diverse repertoire of homeostatic functions also makes them important effectors in atherosclerotic regression (22).

Since the description of the Mononuclear Phagocyte System, the prevailing paradigm was that tissue resident macrophages are continuously seeded from circulating monocytes. In recent years, however, it has become obvious that under homeostasis the tissue macrophage pool is mainly maintained through local proliferation and does not solely depend on monocyte influx (23-25). Monocyte-independent seeding of resident tissue macrophages starts early in embryonic development. Macrophages originating from the extra-embryonic yolk sac (YS) populate tissues during embryonal development as erythro-myeloid progenitor (EMP)-derived macrophages and persist into adulthood $(26,27)$. Microglia in the central nervous system are for instance exclusively derived from YS progenitors, without input from blood monocytes $(28,29)$. However, in most organs, a second wave of monocyte-derived macrophages, originating from definitive haematopoietic stem cells within the fetal liver and bone marrow (BM), co-colonize the tissues $(30,31)$. The question of tissue macrophage ontogeny has critical implications. EMP-derived macrophages migrate to tissues at the time of organogenesis and seem indispensable in various developmental processes (32-36). This developmental and homeostatic function might prevail in adult life, generating an important link between macrophage ontogeny and function. Indeed, we and others have found that macrophages of different ontogeny perform distinct tissue-specific functions and maintain a specific phenotype (37-41). Delineating monocytemacrophage ontogeny and trafficking might improve our understanding of the maladaptive chronic inflammatory response in atherosclerosis development, as well as their role in atherosclerosis regression. Ultimately, this could lead to targeted approaches tackling the high rates of global cardiovascular mortality and morbidity resulting from atherosclerosis.

In this Review we address the knowns and unknowns of the trafficking, dynamics and fates of vascular monocytes and macrophages in the healthy and atherosclerotic aorta. Analysing these properties in human tissues is complicated by the availability of human material and models. Therefore, we will focus primarily on results from the mouse as a model organism but put these results into human context where possible at the end of this Review.

\section{MONOCYTES AND MACROPHAGES IN THE HEALTHY AORTA}

The development and broad accessibility of novel highdimensional analysis techniques, such as multi-parameter flow cytometry, single-cell RNA sequencing (scRNA-seq) and cytometry by time of flight, has enabled scientists to obtain a clearer picture of leukocyte diversity in the healthy mouse aorta. These studies revealed that myeloid cells, and in particular macrophages, are the dominant immune cell type in the healthy arterial wall $(16,37,42,43)$. Arterial macrophages are primarily located in the fibrous outer arterial layer, the adventitia. Only a small number of macrophages can be found in the innermost layer, the intima, just below the endothelial cells. Based on histological and scRNA-seq data, it's estimated that up to $10 \%$ of the arterial macrophages are located in the intima, whereas $90 \%$ are positioned within the adventitial layer $(16,37,44)$.

The aorta is populated with macrophages early on during embryonic development. Macrophages can be observed in the fetal aorta at embryonic day 16.5 and most likely start inhabiting the niche from embryonic day 9.5 onwards $(27,32,44)$. This prenatal wave of macrophages colonising the aorta is dominated by YS EMP-derived macrophages which travel to the aorta without a monocyte intermediate. After birth, the brief influx 
of blood monocytes, which consequently differentiate into tissue resident macrophages, contributes to the aortic macrophage pool $(37,44)$. Despite the monocytic influx, YS EMP-derived macrophages are not replaced by BM-derived macrophages, as has been suggested previously. Rather, the entire adventitial macrophage pool of EMP- and BM-derived macrophages continues to expand in numbers until 45 weeks of age, with YS EMP-derived macrophages being the dominant tissue-resident macrophage population (Figure 1). In aged mice, at around 90 weeks, a general drop of adventitial macrophage numbers mainly affecting EMP-derived macrophages can be observed (37). In contrast to adventitial macrophages, macrophages residing in the intima have recently been reported to seed almost exclusively after birth (16). Using various mouse models, including CD115, CX3CR1 and Flt3 reporter mice, Williams et al. showed that the macrophages inhabiting the intimal layer originate exclusively from definitive haematopoiesis. Interestingly, intimal macrophages are primarily found in locations of increased hemodynamic stress, which are predilection sites for atherosclerosis development $(2,3)$. Although we did not specifically investigate this aspect, our results show no site-specific tropism of adventitial macrophages throughout the aortic segments, in contrast to intimal macrophages (37). This puts further emphasis on understanding the origin, dynamics, and function of intima-resident macrophages. Given the critical role of intimal macrophages in atherosclerosis development, it will be interesting to see the results by Williams et al. confirmed with more efficient fate-mapping models, such as the recently generated $\mathrm{Rank}^{\mathrm{Cre}}$ (45) and Ms4a3 ${ }^{\mathrm{Cre}}$ mice (30), in a quantitative approach.

Of note, one group has identified an unconventional Sca$1^{+} \mathrm{CD} 45^{+}$cellular subset in the adult murine aorta, proposed to be adventitial macrophage-committed progenitor cells $(46,47)$. A recent scRNA-seq study also identified an interferon-poised subset of Sca- $1^{+}$aortic macrophages, whereas the macrophage progenitor potential of aortic cells has been questioned by others $(48,49)$. Whether these $\mathrm{Sca}-1^{+} \mathrm{CD} 45^{+}$cells are indeed a macrophage progenitor population or potentially are provided by $\mathrm{Sca}-1^{+}$mesenchymal stem cells remains to be elucidated $(43,50-54)$.

Under homeostasis, the adult arterial macrophage pool experiences little dynamic. Adventitial EMP- and BM-derived

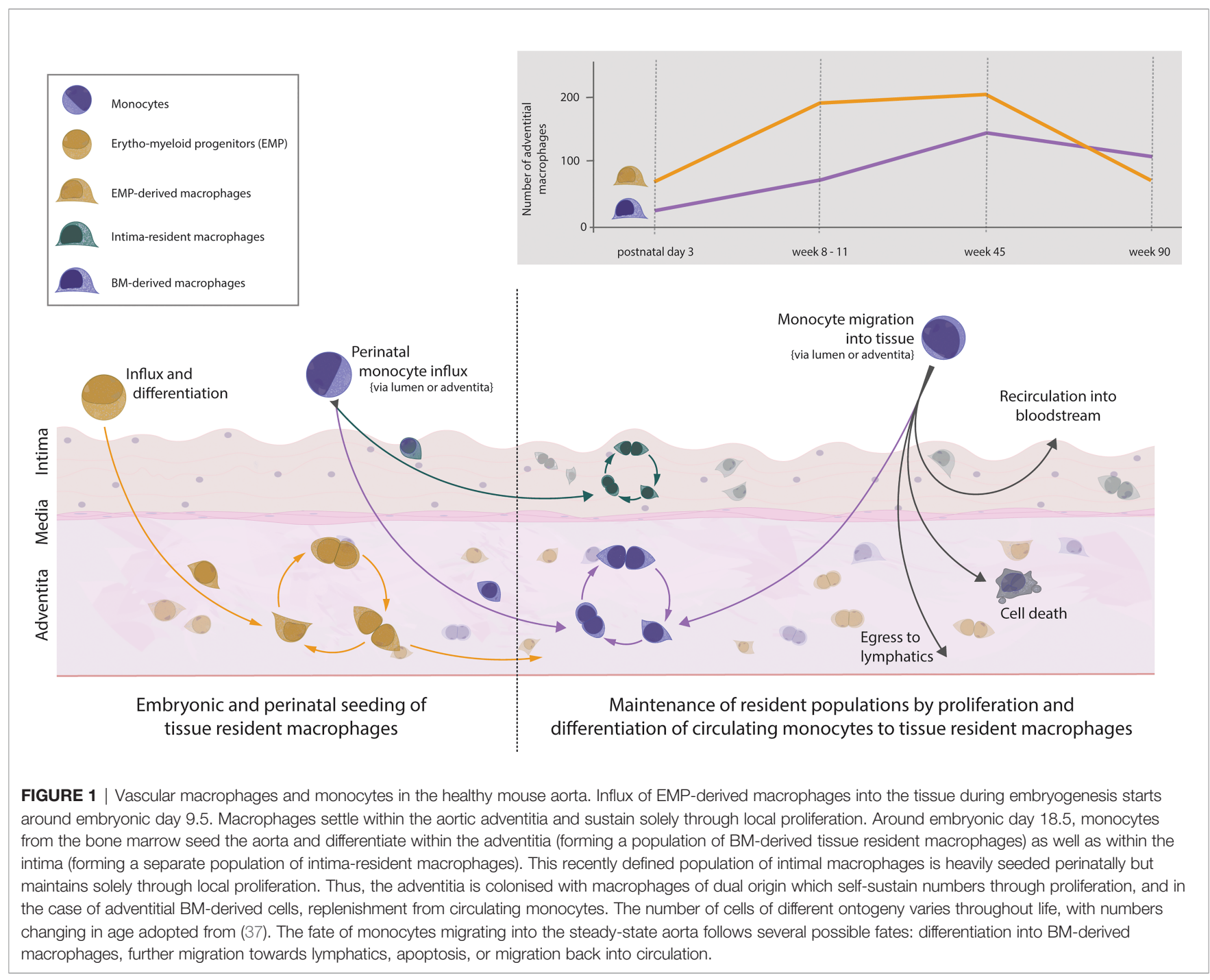


macrophages self-maintain with minimal input from monocytes entering the arterial wall. Using irradiation-free chimeras and parabionts, we and others have found that over a period of 9 months, only $20 \%$ of the arterial macrophages are replenished by monocytes $(37,44)$. In addition, this number seems to be a constant, as we observed a similar $20 \%$ monocyte input after a 3month observation period (37). Contrary to the macrophages residing in the adventitia, the intimal macrophages appear to not be replaced by monocytes under homeostasis (16).

Besides the quantitatively limited replenishment of the macrophage pool in the adventitia, monocytes have important homeostatic functions in the vasculature. Non-classical Ly6C ${ }^{\text {low }} \mathrm{CCR} 2^{-}$monocytes, which derive from Ly6C ${ }^{\text {high }} \mathrm{CCR} 2^{+}$ in mice, crawl along the endothelium to survey the cellular integrity and sense dangers, as well as to remove cellular debris (55-57). Ly6C ${ }^{\text {low }}$ monocytes are, however, thought to rarely cross the endothelial barrier into the tissue $(57,58)$. In contrast, classical Ly6 $\mathrm{C}^{\text {high }}$ monocytes are highly mobile and extravasate, mainly guided by their CCR2 expression. A population of transiently sessile monocytes has been found in the lungs and skin of mice in their steady-state (59). These 'tissue monocytes' have previously also been identified in the spleen, which acts as a reservoir to quickly mobilize immune cells upon inflammation (60). Contrary to splenic monocytes, the Ly6C ${ }^{\text {high }}$ monocytes in lung and skin can survey the tissue environment and transport antigens to lymph nodes (59). Although the question of sessile monocyte existence has not been addressed for the arterial wall, monocytes are readily identified in the healthy arterial wall $(3,42,43,61)$. Their homeostatic turnover and ability to recirculate into the blood or leave via afferent lymphatics into adjacent lymph nodes, similarly to the surveying monocytes in lung and skin, remains to be determined.

The high motility of Ly $6 \mathrm{C}^{\text {high }}$ monocytes comes with the price of potentially spreading infectious agents $(62,63)$. This might in part explain the presence of infectious agents within atherosclerotic plaques (64). A remaining question is the location of vessel wall entry of Ly6 $\mathrm{C}^{\text {high }}$ monocytes. It has not yet been clarified if and to what extent classical Ly6C $\mathrm{C}^{\text {high }}$ monocytes enter the healthy vascular wall via vasa vasorum in the adventitia or from the luminal side. This is of particular interest in advanced plaques, where intra-plaque sprouting of leaky vessels occurs and could drive the chronic inflammation through the constant supply of monocytes (65).

Analogous to the heterogenous homeostatic functions of monocytes, we and others have found that resident adventitial macrophages have a diverse functional outfit. Traditionally, macrophages have been divided in classically activated M1 and alternatively activated M2 macrophages (66). These two states are, however, in vitro-based extremes on opposite poles of a continuum of macrophage functionality. Novel multiparametric analysis methods have established the high plasticity and different nuances in the macrophage functional outfit (67-69), also in the aortic wall. Recent integrated analyses of scRNA-seq datasets from healthy and atherosclerotic mouse aortas revealed the presence of 5 major macrophage subsets $(70,71)$. As described in more detail below, these subsets are (I) inflammatory, (II) triggering receptor expressed on myeloid cells 2 (TREM2) ${ }^{+}$, (III) interferon inducible, (IV) resident-like and (V) cavity macrophages. These five subsets can be found both in the atherosclerotic and healthy aorta, although the complexity of macrophage phenotypes increases in atherosclerotic aortas $(70,71)$. Strikingly, by employing scRNAseq in Rank ${ }^{\mathrm{Cre}}$ Rosa26 $6^{\text {eYFP }}$ mice we were able to map the transcriptional heterogeneity in adventitial macrophages to their origin. The healthy mouse adventitia harbours a macrophage subset with a homeostatic and anti-inflammatory transcriptional profile that derives almost exclusively from YS EMPs. These macrophages were characterised by a high expression of the hyaluronan receptor encoding gene Lyve-1, a known marker for resident macrophages, which maps them to the macrophage subset responsible for the regulation of aortic collagen production (14), and to the resident-like macrophages described above. Furthermore, EMP-derived macrophages expressed high levels of stabilin 1 (Stab1) and growth arrest specific 6 (Gas6), both of which are important for efferocytosis, a process crucial for the inhibition of atherosclerosis $(37,72-74)$. In contrast, a cluster that lacked eYFP transcript expression and was comprised of monocyte-derived macrophages expressed gene sets that were associated with pro-inflammatory properties, including $\operatorname{Il} \beta$ (37), similar to the subset of inflammatory macrophages. Thus, there seems to be a division of labour in arterial macrophage subsets of different ontogeny, where EMP-derived macrophages are responsible for homeostatic processes like collagen production and efferocytosis. BM-derived macrophages in turn are in a poised state for defending the arterial integrity against pathogens. Thus, it would not be surprising if macrophages of diverse origins play different roles during atherosclerosis progression and regression, given their distinct set of functions.

\section{ENHANCED MONOCYTE INFLUX AND MACROPHAGE PROLIFERATION DURING ATHEROSCLEROSIS DEVELOPMENT AND PROGRESSION}

The intima-resident macrophages are among the first cells exposed to the increased influx of apoB-containing lipoproteins during hypercholesterolemia. These cells are critical in atherosclerosis initiation. The aorta of mice engineered to lack aortic intima-resident macrophages displays decreased lipid deposition in the early stages of atherosclerosis $(4,16)$. Within days of sustained hypercholesterolemia, the capacity of macrophages to metabolize the accumulating lipids and cholesterol is overwhelmed. This leads to the deposition of lipid droplets within the macrophage cytoplasm, resulting in the typical foam cell appearance, and even macrophage death. Macrophage death and defective clearance are known to be major drivers of the atherosclerotic process $(16,75,76)$.

Initially, foam cells appear to be exclusively derived from resident intimal macrophages in the mouse (16). Of note, in humans, VSMCs also play a role in the early development of foam cells (77). Continuous inflammatory triggering by the 
persistent influx of apoB-containing lipoproteins causes a substantial monocyte recruitment within the first 1-2 weeks of hypercholesterolemia $(16,78,79)$. The subendothelial inflammatory foci lead to the expression of adhesion molecules on activated endothelial cells and the secretion of chemokines, most importantly of CCL2/MCP-1, CX3CL1 and CCL5 (80) These factors are essential for the infiltration of primarily Ly6 $\mathrm{C}^{\text {high }}$ monocytes into the developing atherosclerotic plaque $(81,82)$. Combined absence of all three chemokine-chemokine receptor pairs results in an almost complete inhibition of lesion development (82-84). Intravital imaging studies suggest that the luminal ('inside-out') recruitment is important in the early phases of plaque development, whereas ('outside-in') recruitment via adventitial vasa vasorum is the main route for myeloid cells to enter advanced plaques $(78,85)$. More quantitative approaches with adoptive transfer of monocytes and bead labelling found that both the influx and luminal recruitment routes are important already in early atherosclerotic development, and persist in advanced plaques $(86,87)$. The route of plaque-invading monocytes is an important avenue of research, as these cells have been recognized to fuel the inflammatory reaction in developing plaques and blocking their entry might represent a promising therapeutic target.

In addition to causing a local inflammatory responses and recruitment of $\mathrm{Ly} 6 \mathrm{C}^{\text {high }}$ monocytes into the vessel wall, hypercholesterolemia induces a Ly6 $\mathrm{C}^{\text {high }}$ dominated monocytosis $(81,82)$. Elevated levels of cholesterol in haematopoietic stem cells foster the formation of lipid rafts and stabilisation of growth factor receptors, which promote their myelopoietic activity and monocytosis (88-90). Supplementing the enhanced myelopoiesis in the bone marrow, extramedullary haematopoiesis in the spleen contributes to increased production of monocytes and marked recruitment into the developing atherosclerotic lesion $(60,91)$. Other lifestyle-related factors such as hyperglycaemia or stress also have the potential to enhance myelopoiesis and fuel the cycle of monocyte production and entry into the plaque (92-94). Importantly, the circulating monocytes are poised for pro-inflammatory reactions with increased levels of surface receptors such as CD86 and TLR4, as well as increased levels of reactive oxygen species, among other features (44, 95-97). Thus, hypercholesterolemia leads to augmented recruitment and an increased number of circulating monocytes with a heightened inflammatory potential. A topic that warrants further investigation is the role of recently identified monocyte subsets that appear during inflammatory conditions, such as segregated-nucleus-containing atypical monocytes (98), in atherosclerosis development.

The recruited Ly6C ${ }^{\text {high }}$ monocytes are thought to primarily differentiate into intimal macrophages (75). Data from developing atherosclerotic plaques is lacking, but it is conceivable that Ly6 $\mathrm{C}^{\text {high }}$ monocytes have alternative fates within the lesion (Figure 2). As has been shown for sterile liver injury, Ly6 $\mathrm{C}^{\text {high }}$ monocytes can exhibit distinct monocytespecific functions, including the uptake of trapped apoBcontaining lipoproteins (99-101). In this way, monocytes participate in the vicious cycle of cellular apoptosis and necrosis following the metabolic stress of intracellular cholesterol accumulation. Some Ly6 $\mathrm{C}^{\text {high }}$ monocytes might also recirculate into the blood and lymph and present antigens, including de novo generated autoantigens to the cells of the adaptive immune system $(12,13,59)$. Ly6 $\mathrm{C}^{\text {low }}$ monocytes, on the other hand, show an intensified patrolling behaviour at atheroprone sites, which display increased endothelial damage during hypercholesterolemia $(58,102)$. Despite their main task as patrolling intravascular cells, Ly6 $\mathrm{C}^{\text {low }}$ monocytes can also be found in the atherosclerotic plaque, highlighting their potential to extravasate - although to a lesser extent than classical Ly6 $\mathrm{C}^{\text {high }}$ monocytes $(70,82)$. These cells display an anti-inflammatory transcriptional signature with elevated transcripts for cholesterol efflux and vascular repair, thereby promoting the inflammation resolution (58). It is still debated whether the extravasation of Ly $6 \mathrm{C}^{\text {low }}$ monocytes is of importance in the atherosclerotic disease process (58). If so, the anti-atherosclerotic phenotype of Ly6C $\mathrm{C}^{\text {low }}$ monocytes presumably ameliorates the disease process and enhancing Ly6 $\mathrm{C}^{\text {low }}$ monocyte extravasation might be a potential therapeutic target.

Akin to other chronic inflammatory diseases, the initial, mainly CCR2-dependent, recruitment of monocyte-derived macrophages is a crucial pathomechanism in the development of atherosclerosis (82-84, 103-106). However, as the atherosclerotic lesion progresses, monocyte recruitment becomes less important, as evidenced by studies with CCR2- or monocyte-depletion models $(21,107-109)$. The limited impact of blocking monocyte recruitment on progression of advanced plaques might be due to a failure of monocytes to penetrate the lesion. A recent report suggests that monocytes cannot migrate deeply into the lesion and only accumulate superficially, similar to tree ring formation (87). This is, however, contradicted by results showing migrating $\mathrm{CD} 11 \mathrm{c}^{+}$, which appear to be similar to foamy monocytes or macrophages, within atherosclerotic plaques $(100,101,110)$. Consequently, there might be other reasons for the non-reliance on monocyte entry in progressing plaques, such as local macrophage proliferation, as discussed below.

Hypercholesterolemia leads to a substantial influx of monocytes. It has recently been suggested that the perinatally seeded intima-resident macrophages are completely replaced by invading monocyte-derived macrophages within weeks of hypercholesterolemia (16). Although similar results have been observed for liver Kupffer cells during Listeria infection (111), this contrasts with the fate of adventitial macrophages in other models of sterile and non-sterile aortic inflammation. We and others found that, after a transient recruitment of monocytederived macrophages in the acute phase, the resident macrophage population prevails even in chronic inflammatory models $(37,44)$. Our results focused on adventitial macrophages, but the different response of intimal macrophages in atherosclerosis is an intriguing characteristic that might be contributing to the defective inflammation resolution in atherosclerosis $(61,81)$. Given that in mice the entire adventitial macrophage pool requires approximately one year for a complete cell turnover (44), it is likely that the turnover of intimal macrophages during hypercholesterolemia is accelerated by mechanisms like emigration or cell death, which in turn could 


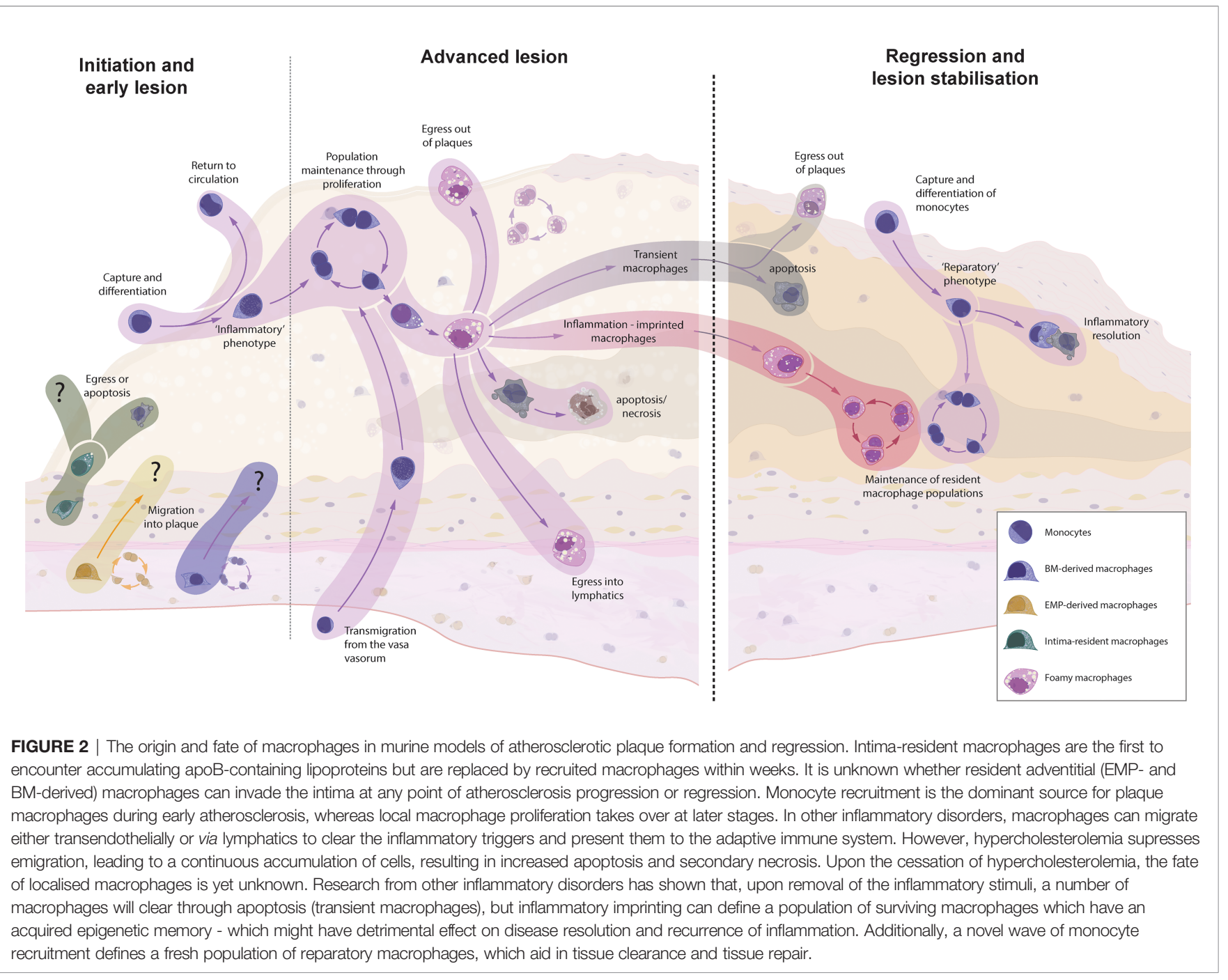

fuel atherosclerotic development. Nonetheless, it is possible that intima-resident macrophage numbers also rebound after the cessation of hypercholesterolemia, but this remains to be elucidated.

The fate of the intima-resident macrophages is of particular interest in the context of atherosclerosis, as we know from other inflammatory conditions that most monocytes recruited under inflammatory conditions do not stably engraft as resident macrophages. These transient macrophages disappear upon the resolution of inflammation $(25,39,112,113)$, which has also been shown in the aorta (44). Future studies will have to elucidate the macrophage composition and origin within the intimal niche after the cessation of hypercholesterolemia. Studies focussing on the lung and other tissues have also found that some de novo recruited macrophages are not transiently resident but persist even after inflammation resolution. Importantly, these macrophages were shown to acquire an epigenetic memory of the inflammatory situation (inflammation-imprinted resident macrophages), which might have detrimental effects on tissue repair or repetitive insults (113). Whether the newly recruited atherosclerotic macrophages share fates with inflammatory macrophages in other tissues and vanish after removal of the inflammatory stimulus is the topic of ongoing research.

Despite the increased macrophage apoptosis and necrosis in atherosclerotic plaques, macrophage numbers are stable throughout disease progression (49). It has been estimated that in early atherosclerosis monocyte recruitment accounts for approximately $70 \%$ of the macrophage replenishment, while more than $85 \%$ of the macrophages in advanced plaques stem from in situ proliferation (49). Interestingly, whereas proliferation of intimal macrophages increases as the atherosclerotic lesions progresses, adventitial macrophages do not proliferate more, as if they were not affected by the ongoing inflammatory process (49). Macrophage loss in atherosclerotic plaques is mainly a result of cell death. In infectious settings, macrophages emigrate from the site of infection either via reverse transendothelial migration or via lymphatics to clear the inflammatory triggers and present them to the adaptive immune system $(62,114)$. Hypercholesterolemia, however, suppresses emigration signals via CCR7 and macrophage 
migratory capacity, leading to a continuous accumulation of macrophages and increased local cell death with the development of a necrotic core $(62,115-118)$. In general, the migration behaviour of plaque macrophages has been characterised as 'dancing on the spot', i.e. macrophages do not migrate within the plaque but only extend and retract their dendrites $(87,110,119)$. This inability to migrate begs the question whether resident adventitial macrophages are capable of crossing the muscular media and migrate into the developing plaque.

Phenotype and functions of macrophages are governed by transcriptional regulation. It has been suggested that the transcriptional programs of intima-resident macrophages and recruited monocyte-derived macrophages converge on a similar foamy macrophage profile early in hypercholesterolemia (16, 71). But developing atherosclerotic plaques harbour many heterogenous subsets of macrophages. As described above, efforts to integrate the various scRNA-seq studies of the murine atherosclerotic plaque have defined 5 distinct macrophage subsets: (I) inflammatory, (II) TREM2 ${ }^{+}$, (III) interferon inducible, (IV) resident-like and (V) cavity macrophages $(70,71)$. Inflammatory macrophages show elevated expression levels of pro-inflammatory cytokines like interleukin $1 \beta$ and tumor necrosis factor. The strong proinflammatory gene profile and the importance of interleukin $1 \beta$ in atherosclerotic disease points towards a major role of this macrophage subset in aggravating the chronic atherogenic inflammation. These cells were furthermore characterized by high CCR2 expression and presumably are transient inflammatory macrophage descendants from invading Ly6C ${ }^{\text {high }}$ monocytes. Macrophages expressing TREM2 have been identified as the foam cell population in atherosclerotic plaques $(120-122)$. TREM2 is a transmembrane glycoprotein that can interact with apolipoprotein $\mathrm{E}$ and $\mathrm{TREM} 2^{+}$macrophages show a transcriptomic signature enriched for lipid metabolism pathways, pinpointing their role in lipid and cholesterol handling $(38,123)$. TREM $2^{+}$macrophages have previously been shown to possess anti-inflammatory functions (124). The $\mathrm{TREM}^{+}$macrophage subset in atherosclerotic plaques is also characterized by dramatically decreased expression levels of proinflammatory molecules like interleukin $1 \beta$, tumor necrosis factor or NLR family pyrin containing domain 3 (Nlrp3) (120, 121). Furthermore, TREM $2^{+}$macrophages have been found to express increased levels of CD11c (110), similar to foamy monocytes $(100,101)$. Interestingly, TREM2 expression is found in a variety of disease-associated macrophages, including microglia during neurodegenerative disease and lipid-associated macrophages in obesity $(38,125)$. Even in our dataset of adventitial macrophages during angiotensin II-induced arterial inflammation, we were able to identify TREM $2^{+}$macrophages (71). Consequently, TREM $2^{+}$macrophages might represent a phenotype that is associated with tissues exhibiting increased lipid deposition and apoptosis. In both scenarios, macrophages capable of handling lipid depositions are required for tissue homeostasis. Additionally, apoptotic cell death, which leads to increased lipid and cholesterol deposition, is associated with anti-inflammatory cell functions (76). It is interesting to note that TREM $2^{+}$macrophages do not seem to be related to only one ontogeny but can derive from both YS and BM $(38,71,125)$. The interferon-inducible macrophages are a rather small subset in the atherosclerotic plaque (70). These macrophages are characterised by expression of several interferon-inducible genes, including Isg15 and Irf7. Future studies will have to investigate this so far unknown subset but given the pro-atherosclerotic role of type I interferon signalling, interferon-inducible macrophages might be detrimental in the course of the disease (126). The identified resident-like macrophage subset is characterised by high expression of Lyve-1, a gene that is important in resident adventitial macrophages for regulation of collagen production in the arterial wall (14). Similar to our dataset of Lyve-1 expressing macrophages in the healthy aorta (37), resident-like macrophages in the atherosclerotic plaque showed increased gene expression of Gas6 $(48,70,121)$. Consequently, residentlike macrophages might be important in the efferocytotic clearance of apoptotic plaque cells and thus be major influencer of the balance between progressing and regressing atherosclerotic plaques. A drawback of the scRNA-seq studies is that we cannot distinguish between intimal and adventitial macrophages. Thus, the presence of resident-like macrophages in atherosclerotic aortas does not provide evidence for a role of Lyve- $1^{+}$resident macrophage in the intima-focussed atherosclerotic disease process. The discovery of a macrophage subset expressing a gene signature reminiscent of 'cavity macrophages' is an interesting aspect, in light of recent reports. Mature macrophages from serous cavities like the peritoneum or pericardium have been shown to invade surrounding tissue during sterile inflammation where they play important roles during tissue repair (127-129). The presence of cavity macrophages in atherosclerotic aortas indicates that adjacent macrophages, from serous cavities or potentially even the adventitia, can invade the atherosclerotic aorta and intima.

Even though resident adventitial macrophages constitute $90 \%$ of the aortic macrophages and are the only arterial subset originating from EMPs, their involvement in the atherosclerotic disease process is unclear. The role of adventitial macrophage subsets, including the YS EMP-derived adventitial macrophages, warrants further investigation. As described above, EMP-derived adventitial macrophages show a distinct transcriptional signature of anti-inflammatory and efferocytic functions, that is preserved during chronic arterial inflammation (37). Failing efferocytosis, in particular, has been shown to be a major pathogenic factor in atherosclerotic development (76). Adventitial EMP-derived macrophages seem to be predestined to counteract this failure and inhibit the inflammatory cycle within atherosclerotic plaques - if they invade the growing lesion. As outlined herein, plaque macrophages show diminished migratory behaviour, and adventitial macrophages are not thought to invade the growing plaques. On the other hand, the presence of cavity macrophages suggests that certain macrophage subsets might still be able to invade the developing lesions. Also, a CD $11 c^{+}$cell subset, which resemble foamy macrophages, has been shown to be actively migrating within the plaque. These results warrant further 
investigation on the trafficking of adventitial macrophages and macrophages of different ontogenies during the various stages of atherosclerosis development.

\section{MACROPHAGE EGRESS AND MONOCYTE MIGRATION IN REGRESSING ATHEROSCLEROTIC PLAQUES}

Atherosclerosis is characterised by a failure to resolve the inflammatory response. The continuous influx and retention of apoB-containing lipoproteins represents a persistent inflammatory stimulus. The lowering of blood lipid levels, in particular cholesterol levels (130), allows the resolution phase to commence. The resolution or regression of atherosclerotic plaques can lead to a reduction of plaque size, but most importantly results in the scarring and stabilisation of advanced lesions, lowering the risk of myocardial infarction and stroke (22). The reduction of plaque leukocyte abundance and a phenotypic switch in plaque cells are important hallmarks during atherosclerosis regression (131). Macrophages are highly plastic cells, and as such are fundamental players in the tissue repair processes seen in atherosclerosis regression.

Traditional mouse models of atherosclerosis, like the LDL receptor and apolipoprotein $\mathrm{E}$ knockout mouse, have greatly contributed to our understanding of the atherosclerotic disease process. These models, however, lack the ability to normalise hypercholesterolemia and induce regression. Fortunately, in recent years several mouse models of atherosclerosis regression were developed (132-138). The common denominator of these models is the normalisation of cholesterol levels after a phase of hypercholesterolemia to induce advanced atherosclerotic plaques. Examples include the transplantation of atherosclerotic aortic segments into normocholesterolemic mice or the inducible deficiency of the microsomal triglyceride transfer protein, as in the Reversa mouse $(132,133)$. The variety of regression models, as well as their individual limitations, such as surgical inflammation and a lack of lymphatic anastomosis in the transplantation model might be the reason for the heterogeneous results regarding the fate of macrophages in atherosclerosis regression. A novel approach uses antisense oligonucleotides, targeting the LDL receptor to transiently cause hypercholesterolemia and induce atherosclerotic plaques. In this model, regression can be induced either by discontinuing the antisense oligonucleotides or through treatment with sense oligonucleotides for the LDL receptor (136). The LDL receptor antisense method offers a promising approach, as it allows scientists to omit time- and labour-intensive crossbreedings when using transgenic animals in regression. Furthermore, due to its limited off-target effects, antisense treatment is even used in human hyperlipidaemic disease $(139,140)$.

A hallmark of atherosclerosis regression is the reduction of the plaque macrophage content $(87,117,141-146)$. Macrophage emigration from arteries via afferent lymphatics or reverse transendothelial migration aids the host defence by presenting antigens to the adaptive immune system $(62,114)$. As described above, hypercholesterolemia blunts the CCR7-guided emigration via the expression of neuroimmune guidance cues, including netrin 1 and semaphoring 3E, and by increasing plasma membrane cholesterol content which affects intracellular signalling as well as other mechanisms $(62,115-118,147)$. Not surprisingly, the reversal of hypercholesterolemia has been shown to induce CCR7 expression in plaque macrophages and with it their efflux via afferent lymphatics (117, 142-144, 148150). Whether lesional macrophages leave the regressing plaque via reverse transendothelial migration, as well as the quantitative relevance of macrophage emigration to the overall loss of plaque macrophages has not yet been clarified. Increased macrophage emigration has been observed in several different models of atherosclerosis regression, including the aortic transplantation, the Reversa mouse and apoB-targeted antisense oligonucleotide treatment $(117,142-144,148-150)$, whereas other reports have found no difference in macrophage emigration behaviour during regression $(87,145,146)$. Importantly, emigration of plaque macrophages to lymph nodes might aid the development of the recently described post-resolution phase, although it is unknown whether this establishment of adaptive immunity takes place in atherosclerosis regression (151).

Another common mechanism of leukocyte removal during tissue repair is programmed cell death via apoptosis (152). Effective clearance of apoptotic cells by macrophages avoids secondary necrosis and suppresses inflammation. Additionally, efferocytosis aids tissue repair by inducing a pro-resolving phenotype in phagocytosing macrophages (76). Whereas a recent report identified increased macrophage apoptosis as part of the regression mechanism (149), other studies did not find elevated numbers of apoptotic macrophages in regressing plaques $(145,146,150)$. In order for apoptosis to act as a proresolving stimulus, efferocytosis needs to be functional. In atherosclerosis progression, however, defective efferocytosis is an essential pathogenic mechanism (11). The role of macrophage apoptosis in atherosclerosis regression remains elusive, and further studies investigating the presence and functionality of efferocytosis in atherosclerosis regression are warranted.

As macrophage numbers in advanced atherosclerotic plaques are primarily maintained through local proliferation, another means of reducing the plaque macrophage burden is through the suspension of proliferation. Indeed, a decrease in proliferating macrophages can be observed within 3 weeks of regression (145, 149). An inhibition of macrophage proliferation upon cessation of hypercholesterolemia is not an unexpected finding, as the retained and modified apoB-containing lipoproteins are potent inducers of M-CSF, contributing to an increase in local macrophage proliferation in advanced plaques $(49,153,154)$.

In addition to macrophage survival and proliferation, monocyte recruitment is another factor influencing plaque macrophage numbers. The reversal of hypercholesterolemia presumably blunts the heightened monocytopoiesis and normalises circulating Ly6 $C^{\text {high }}$ monocyte levels. However, so far, no difference could be detected in studies evaluating the monocyte frequency even after 4 weeks of regression $(145,146)$. These intriguing results warrant 
further studies focusing on the timing and return to a steady-state haematopoiesis following the onset of normocholesterolemia. Nonetheless, monocyte extravasation is not only dependent on the number of circulating monocytes, but also on their potential to invade the regressing plaque. Similarly to mechanisms halting proliferation of plaque macrophages, decreased de novo generation of macrophages from immigrating monocytes would result in a reduction of plaque macrophage abundance. Experimentally, several groups have detected a suppressed migration of Ly6C $\mathrm{C}^{\text {high }}$ as well as Ly6C ${ }^{\text {low }}$ monocytes into the regressing plaque by using the adoptive transfer of labelled monocytes, as well as by monocyte tracking with fluorescent beads $(145,146,155)$. The quantitative relevance of this effect might, however, be limited. Härdtner et al. estimated that the limited monocyte recruitment accounts for only about $25 \%$ of plaque macrophage reduction (145), whereas another report found no suppression of monocyte influx in regressing plaques, despite using similar methods (149). In summary, there are various mechanisms at play reducing the abundance of inflammatory macrophages in regressing atherosclerotic plaques. Presumably, all four mechanisms mentioned herein are relevant for ameliorating the inflammatory burden, likely occurring at various stages of regression. Longitudinal studies of macrophage trafficking, in combination with fate-mapping models and other methodologies capable of tracing the fates of lesional macrophages will hopefully advance our understanding of the cellular dynamics in regression.

The diminished monocyte influx during atherosclerosis regression is an interesting avenue for further research. The resolution and repair phase after myocardial infarction, as well as following sterile injuries in other organs, depends on the continuous influx of monocytes, which consequently differentiate into reparatory and pro-resolving macrophages (156-160). The importance of monocyte migration into the arterial wall to facilitate inflammation resolution and tissue repair has recently also been established for atherosclerosis regression. Applying the aortic transplantation models in numerous chemokine receptor knockout and reporter mice, Rahman et al. found that inhibiting the entry of Ly6 $C^{\text {high }}$, but not Ly6 $\mathrm{C}^{\text {low }}$ monocytes, into the atherosclerotic plaque during normocholesterolemia abrogates atherosclerosis regression (161). Analogous to their phenotype in the steady-state, Ly6C $\mathrm{Cigh}^{\text {h }}$ monocytes might not necessarily differentiate into macrophages, but instead participate in tissue repair with their monocytespecific functions. In a model of sterile liver injury, as well as during the resolution phase after myocardial infarction, recruited classical Ly6C ${ }^{\text {high }}$ monocytes performed a phenotypic switch to non-classical Ly6C ${ }^{\text {low }}$ monocytes, which was crucial for optimal tissue repair $(99,157)$. The precise functions of circulating Ly6C $^{\text {low }}$ monocytes during atherosclerosis regression have not yet been clarified. Given their role in the integrity of the endothelium, it is conceivable that intravascular Ly6C ${ }^{\text {low }}$ monocytes participate in the reorganisation of the endothelial layer during the plaque size reduction. It will be interesting to see first results of studies focussing on the role Ly6 $\mathrm{C}^{\text {low }}$ monocytes during atherosclerosis regression, for instance in a mouse model with a Ly6C ${ }^{\text {low }}$ monocyte-specific deficiency (162).
Akin to the inflammation-poised phenotype of monocytes circulating during hypercholesterolemia and atherosclerosis development described above, resolution-dedicated monocyte subsets have been found to be present in the inflammatory resolution of sepsis and colitis (163). However, as to whether the reparatory $\mathrm{Ym} 1$ (chitinase-like protein 3$)^{+} \mathrm{Ly} 6 \mathrm{C}^{\text {high }}$ monocyte subset described is also present during atherosclerosis resolution has not been investigated. Nevertheless, Ly6 $\mathrm{C}^{\text {high }}$ monocytes have been found to exhibit an altered surface expression of various proteins during the regression of atherosclerosis (146). This underlines the importance of the quality over the quantity of the monocyte response and offers an explanation as to why atherosclerosis regression continues undisturbed in studies with suppressed monocyte recruitment.

Emerging scRNA-seq studies of atherosclerosis regression have been providing us with an insight regarding the heterogeneity of the remaining and recruited macrophages in regressing plaques $(48,149)$. Interestingly, the same, previously mentioned, five main macrophage clusters present during atherosclerosis have also been observed in regressing plaques (48, 70, 149). This might be less surprising for the subsets of cavity-like and TREM2 ${ }^{+}$macrophages. As mentioned above, cavity macrophages have been found to be essential mediators of tissue repair (127-129). The scRNA-seq studies of atherosclerosis regression, however, are unable to inform us about the location of the analysed macrophages, and thus it is unclear as to whether these cavity macrophages have invaded the intima, or if they participate in the resolution of the intimal inflammation However, TREM2 ${ }^{+}$macrophages are known to be equipped for lipid handling, and the accumulation of extracellular lipids is part of the tissue repair when dead and apoptotic cells need to be cleared by efferocytosis, a process that is increased in regressing plaques (149).

Although these studies identified the same major macrophage clusters in regressing plaques as in atherosclerosis development, there were subtle differences in expression levels representing a spectrum of activation states $(48,149)$. The subset of inflammatory macrophages, for instance, showed decreased expression levels of Il1 $\beta$ and Nlrp3, compared to atherosclerotic macrophages before the induction of atherosclerosis regression (149). Interestingly, the described interferon-inducible macrophages had increased transcription levels of signal transducer and activator of transcription 6 (Stat6), which is known to induce type 2 or reparatory immune responses (149). Notably, when atherosclerotic aortic segments were transplanted in normocholesterolemic Stat6-deficient mice, atherosclerosis regression was abrogated, which was associated with a proinflammatory phenotype of plaque macrophages (161). A question that has not been finally resolved is if the already present plaque macrophages can be repolarized by the regressing conditions to adjust their functional program towards a reparatory phenotype or if an influx of de novo reparatory macrophages is required. The study by Rahman et al. found that Ly6 $\mathrm{C}^{\text {high }}$ monocyte influx is an absolute requirement for plaque regression and differentiation of reparatory macrophages (161). This is in line with evidence that 
inflammatory macrophages cannot be repolarized to reparatory macrophages (164) undefined. In other reports inflammatory macrophages could be repolarized to a reparatory phenotype, although only a limited number of phenotypic markers were assessed (165, 166). Furthermore, an elegant in vivo tracking approach found a phenotypic adjustment of individual macrophages from inflammatory inducible nitric oxide synthase-expressing to arginase-expressing macrophages in a model of chronic central nervous inflammation (167). If and to what extent a local phenotypic switch of macrophages occurs in the regressing atherosclerotic plaque remains elusive and warrants further studies.

Interestingly, when Lin et al. broke down the transcriptional differences in macrophages during progression and regression in more detail, they identified one substantial macrophage subset and 42 distinctly regulated genes that were predominantly present during regression. The macrophage subset was characterised by high expression of Stab1, which is important for efferocytosis. In addition to Stab1, Gas6 represents another upregulated molecule important for efferocytosis (48). Intriguingly, we have previously found that adventitial EMPderived macrophages are characterised by high expression levels of both Stabl and Gas6 (37). The presence of a regressionspecific macrophage subset expressing a similar signature might indicate a role for EMP-derived macrophages in the tissue repair during atherosclerosis regression, and even hint towards the migration of these prenatally seeded adventitial macrophages into the intima. Relatedly, EMP-derived macrophages are known to be important regulators of tissue repair in the heart $(168,169)$. So far, it was assumed that adventitial macrophages do not cross the media and immigrate into the intima, but future studies will have to re-evaluate the fate of adventitial EMP-derived macrophages during atherosclerotic disease.

\section{HUMAN TRANSLATABILITY}

The wide array of available methods, including genetic fatemapping models, intravital imaging or tracking of adoptively transferred cells, makes the mouse an ideal model system for studying the trafficking behaviour and dynamics of monocytes and macrophages. Although these models allow us to study the trafficking of mononuclear phagocytes in the mouse vasculature, ultimately the goal is to advance our understanding of these features in the human-being. Since similar scientific manipulations are unfeasible in the human, descriptive studies are used to determine the translatability of results in the mouse to the human situation.

In mice YS EMP-derived macrophages seed the aorta during early embryonic development. Haematopoiesis is a conserved process between men and mice, with an initial haematopoietic wave originating in the extra-embryonic YS, followed by a transition to intra-embryonic definitive haematopoiesis (170, 171). We and others have previously identified primitive macrophages in the human YS that show a phenotype similar to mouse EMP-derived macrophages in the mouse $(27,172,173)$.
A recent study employing scRNA-seq on human embryonic tissue at different time points of organogenesis found tissueresident macrophages originating from the YS as well as the fetal liver (174), thus providing evidence for an initial seeding of vascular macrophage during early human embryogenesis and corroborating rodent studies. A second wave of monocytederived macrophage presumably follows the initial seeding with YS-derived macrophages in the human. Direct evidence for this in the arterial wall is lacking but studies in other human tissues were able to translate the results of mouse studies to humans. Langerhans cells in the skin have been shown to be YSderived resident epidermal macrophages seeding the tissue in the first wave, whereas dermal macrophages are of monocytic origin in mice $(31,175)$. In humans with an inherited severe monocytopenia, a dramatically reduced frequency of $\mathrm{CD} 14^{+}$ dermal macrophages but sustained numbers of Langerhans cells could be observed $(176,177)$. The skin is an easily accessible organ with different macrophage ontogenies that enables investigation of macrophage trafficking in humans. Other future options might include the study of conserved epigenetic marks between the murine and human system also in the cardiovascular system and especially the arterial wall.

Like in the mouse, macrophages are a major subset or even the dominant immune subset in the non-atherosclerotic arterial wall of humans, although the human arteries also contain significant numbers of $\mathrm{T}$ lymphocytes $(16,37,42,43,178-$ 180). Arterial phagocytes can be found in the intima, directly beneath the endothelial layer, mirroring their function as immune sentinels, as well as in the adventitia (2, 180-185). Arterial resident macrophages are more prevalent in the adventitial layer than in the intima, although the difference is less pronounced compared to the mouse $(186,187)$. As would be expected for immune sentinels, intima-resident macrophages can be found more frequently at atheroprone sites, which show non-laminar and low shear stress blood flow $(2,180,183)$. Studies in other human organs have provided evidence that tissue-resident macrophages self-sustain mainly through local proliferation without monocyte input, although there might be differences depending on the macrophage subset. In studies of sex-mismatched hand allografts, YS-derived Langerhans cells were not replaced by recipient cells but remained of donor origin up to 10 years post-transplantation $(188,189)$. This is in line with results of sex-mismatched heart transplants, where only $31 \%$ of presumably BM-derived CCR $2^{+}$macrophages were of recipient origin compared to less than $1 \%$ CCR2-, potentially YSderived, resident macrophages, after a mean period of 8.8 years post-transplantation (190). The arterial wall of the vessels in the transplanted organs has not been examined separately, but a recent scRNA-seq study of human healthy arterial tissue identified a proliferative macrophage subset (178), hinting towards a self-sustaining arterial resident macrophage population.

Although the human intima harbours subendothelial macrophages and $\mathrm{CD} 11 \mathrm{c}^{+}$phagocytes that mirror the recently identified aortic intima-resident macrophage of the mouse (16, $181,191)$, there are important differences in the intimal composition between mouse models and humans that need to 
be considered. The human intima is thickened and comprises abundant VSMCs and extracellular matrix at sites prone to atherosclerotic development. Additionally, VSMCs are very plastic cells and in addition to being producers of extracellular matrix components can be phagocytic and develop into foam cells. The discrimination of VSMC and macrophage foam cells is complicated by the fact that, VSMCs can express macrophage markers like CD68, whereas macrophages have also been found to express VSMC lineage markers (51, 192-195). Lineage-tracing studies in mice have shown a varying degree of foam cells originating from VSMCs, ranging from $16 \%$ to $70 \%(53,195-$ 197). In humans, it has been estimated through the analysis of histone marks that $18 \%$ of $\mathrm{CD}^{+} 8^{+}$plaque cells originate from the VSMC lineage (51). Future studies will have to determine to what extent VSMCs and macrophages contribute to the foam cell pool at different phases of the atherosclerotic process.

The inflammatory reaction following the influx, retention and modification leads to a continuous recruitment of human monocytes into the growing atherosclerotic lesion (198, 199). Evidence for an important role of monocyte recruitment in the development of human atherosclerosis derives from studies showing an association of monocyte counts with atherosclerotic plaque development during several years of follow-up (200-202). Human monocytes can be distinguished into three different subsets: (I) classical CD14 ${ }^{+} \mathrm{CD} 16^{-}$, analogous to the Ly6C $\mathrm{C}^{\text {high }}$ mouse population, (II) non-classical $\mathrm{CD} 14^{\mathrm{dim}} \mathrm{CD} 16^{+}$, aligning with the murine Ly6 $\mathrm{C}^{\text {low }}$ subset, and (III) intermediate $\mathrm{CD} 14^{+} \mathrm{CD} 16^{+}$monocytes (203). Emerging results from multiparametric analyses identified further subsets and it will be interesting to determine their functional relevance in atherosclerosis (204-206). The non-classical CD14 ${ }^{\mathrm{dim}} \mathrm{CD} 16^{+}$ monocytes fulfil similar endothelial surveillance functions as in the mouse, whereas the role of intermediate monocytes is not yet clear in the atherosclerotic progress $(55-57,203)$. The classical $\mathrm{CD} 14^{+} \mathrm{CD} 16^{-}$are thought to mainly enter the growing atherosclerotic lesion (207), as this subsets preferentially migrates into tissues and differentiates to macrophages (208211). Consequently, it has been shown that higher numbers of circulating $\mathrm{CD} 14^{+} \mathrm{CD} 16^{-}$monocytes predict cardiovascular events $(212,213)$. Interestingly though, classical $\mathrm{CD} 14^{+} \mathrm{CD} 16^{-}$ monocytes do not associate with a more high-risk plaque phenotype in patients with advanced atherosclerosis (214). This might be owed to a more important role of local macrophage proliferation than monocyte recruitment in advanced atherosclerosis, similar to what has been observed in mice. In line with this, advanced atherosclerotic plaques contain a significant fraction of proliferating macrophages (71, 215-219). Another striking similarity between the human and mouse plaque macrophages relates to their phenotype. An integrated analysis of scRNA-seq subsets of the mouse and human revealed a conserved phenotype between the two species, with detection of (I) inflammatory, (II) foamy TREM $2^{+}$, (III) resident-like and (IV) interferon-inducible macrophages (71).

In summary, there are important differences between human and mouse atherosclerosis, as exemplified by the presence of a thickened VSMC-rich intima in the human arterial wall.
Nonetheless, studies in rodent models have been instructive in examining basic principles of the trafficking of mononuclear phagocytes and will continue to provide valuable insight. Novel techniques, such as spatial transcriptomics (220), hold a great promise in translating murine results to the human situation.

\section{CONCLUSION AND OUTSTANDING QUESTIONS}

Monocytes and macrophages are key effector cells during all phases of atherosclerotic disease. Their trafficking in and out of the arterial wall directly influences the disease process. Although we have gained substantial insight into these processes during atherosclerosis development, there are still major gaps in our knowledge. For instance, it is currently unknown if invading monocytes persist in a non-differentiated state within the plaque or if their only fate is the differentiation to plaque macrophages. Answering this question is complicated by the phenotypic similarities of monocytes and macrophages. The combination of newly developed fate-mapping models with novel methodologies, like spatial transcriptomics, display a promising avenue for future investigations of cellular fates within the plaque. Along these lines, the recently identified subset of intima-resident macrophages illustrates the potential of such methodologies to deciphering macrophage dynamics within the arterial wall by using novel methodologies.

Nonetheless it is unclear if intima-resident macrophages vanish entirely upon onset of hypercholesterolemia or can rebound once cholesterol levels are normalised. Another remaining question relates to the dynamics of replacing intima-resident macrophages by recruited macrophages. Does the resident subset die, emigrate or just stop its proliferation?

Another major remaining question is the role of adventitiaresident macrophages in atherosclerosis. During atherosclerosis development, perinatally seeded intima-resident macrophages are quickly replaced by recruited inflammatory macrophages. The replacing cells are presumably transient macrophages, which do not engraft after inflammation resolution. As mentioned earlier, it is currently unclear whether a small subset of intimaresident prevails during atherosclerosis progression, and whether these cells are capable of rebounding following the cessation of hypercholesterolemia. Consequently, adventitial macrophages might be the only long-term resident macrophages in the aorta during atherosclerosis development. In contrast to the recruited inflammatory macrophages in the intima, adventitial macrophages do not show increased proliferation during atherosclerosis development, resulting in largely stable macrophage numbers despite the continuous inflammation in the local environment (49). This, and the low migratory capacity of plaque macrophages could argue for a limited role of adventitia-resident macrophages in the atherosclerotic process. On the other hand, regressing atherosclerotic plaques contain a subset of macrophages possessing a transcriptional signature that is reminiscent of homeostatic and pro-resolving EMP-derived adventitial macrophages. Future studies will have to evaluate the 
role of adventitial macrophages in atherosclerosis and investigate if these cells are capable of migration into the intima. Given their pro-resolving phenotype, adventitial EMP-derived macrophage and their migration into the atherosclerosis-affected intima also display a potential therapeutic target.

In general, we are lacking studies that quantitatively examine the recruitment and different fates of monocytes and macrophages during the different phases of atherosclerosis progression, and in particular during atherosclerosis regression. Novel fate mapping and conditional gene deletion models, such as the Ms4a3 ${ }^{\text {cre }}(30), C_{C R}{ }^{\text {cre }}(221-223)$ and Rank ${ }^{\text {cre }}$ (45) mice, together with high-dimensional analysis approaches will aid in deepening our understanding of these processes.

In this Review, we have mainly focused on results from mouse models but summarized evidence for similarities as well as differences between the rodent and human arterial wall. Many aspects pertaining the trafficking of monocytes and macrophages are difficult to corroborate in humans, given the unfeasibility of fate-mapping techniques. Nonetheless, the development of novel methods, including scRNA-seq and spatial omics-technologies will continue to expand the possibilities of analysing monocyte

\section{REFERENCES}

1. Roth GA, Abate D, Abate KH, Abay SM, Abbafati C, Abbasi N, et al. Global, Regional, and National Age-Sex-Specific Mortality for 282 Causes of Death in 195 Countries and Territories, 1980-2017: A Systematic Analysis for the Global Burden of Disease Study 2017. Lancet (2018) 392:1736-88. doi: 10.1016/s01406736(18)32203-7

2. Millonig G, Niederegger H, Rabl W, Hochleitner BW, Hoefer D, Romani N, et al. Network of Vascular-Associated Dendritic Cells in Intima of Healthy Young Individuals. Arterioscler Thromb Vasc Biol (2001) 21:503-8. doi: 10.1161/01.atv.21.4.503

3. Jongstra-Bilen J, Haidari M, Zhu S-N, Chen M, Guha D, Cybulsky MI. LowGrade Chronic Inflammation in Regions of the Normal Mouse Arterial Intima Predisposed to Atherosclerosis. J Exp Med (2006) 203:2073-83. doi: 10.1084/ jem.20060245

4. Paulson KE, Zhu S-N, Chen M, Nurmohamed S, Jongstra-Bilen J, Cybulsky MI. Resident Intimal Dendritic Cells Accumulate Lipid and Contribute to the Initiation of Atherosclerosis. Circ Res (2010) 106:383-90. doi: 10.1161/ circresaha.109.210781

5. Hajra L, Evans AI, Chen M, Hyduk SJ, Collins T, Cybulsky MI. The NF-Kappa B Signal Transduction Pathway in Aortic Endothelial Cells Is Primed for Activation in Regions Predisposed to Atherosclerotic Lesion Formation. Proc Natl Acad Sci USA (2000) 97:9052-7. doi: 10.1073/pnas.97.16.9052

6. Yahagi K, Kolodgie FD, Otsuka F, Finn AV, Davis HR, Joner M, et al. Pathophysiology of Native Coronary, Vein Graft, and in-Stent Atherosclerosis. Nat Rev Cardiol (2016) 13:79-98. doi: 10.1038/nrcardio. 2015.164

7. Kwon GP, Schroeder JL, Amar MJ, Remaley AT, Balaban RS. Contribution of Macromolecular Structure to the Retention of Low-Density Lipoprotein at Arterial Branch Points. Circulation (2008) 117:2919-27. doi: 10.1161/ circulationaha.107.754614

8. Steffensen LB, Mortensen MB, Kjolby M, Hagensen MK, Oxvig C, Bentzon JF. Disturbed Laminar Blood Flow Vastly Augments Lipoprotein Retention in the Artery Wall: A Key Mechanism Distinguishing Susceptible From Resistant Sites. Arterioscler Thromb Vasc Biol (2015) 35:1928-35. doi: 10.1161/ atvbaha.115.305874

9. Moore KJ, Tabas I. Macrophages in the Pathogenesis of Atherosclerosis. Cell (2011) 145:341-55. doi: 10.1016/j.cell.2011.04.005

10. Borén J, Chapman MJ, Krauss RM, Packard CJ, Bentzon JF, Binder CJ, et al. Low-Density Lipoproteins Cause Atherosclerotic Cardiovascular Disease: Pathophysiological, Genetic, and Therapeutic Insights: A Consensus and macrophage dynamics in humans. Although several findings in the mouse can be translated to the human, there are differences in the pathological mechanisms, which call for an increased effort in performing human studies.

\section{AUTHOR CONTRIBUTIONS}

LT and CS conceived the idea and article structure. FP and LT wrote and edited the manuscript. FP created the illustrations and CS revised the manuscript and provided oversight. All authors have made a substantial, direct and intellectual contribution to the article and approved the submitted version.

\section{FUNDING}

LT is supported by a Walter Benjamin fellowship of the German Research Foundation (DFG). This study was supported by the DFG, SFB 1123 project A07 to CS.
Statement From the European Atherosclerosis Society Consensus Panel. Eur Heart J (2020) 41:2313-30. doi: 10.1093/eurheartj/ehz962

11. Tabas I. Macrophage Death and Defective Inflammation Resolution in Atherosclerosis. Nat Rev Immunol (2010) 10:36-46. doi: 10.1038/nri2675

12. Lorenzo C, Delgado P, Busse CE, Sanz-Bravo A, Martos-Folgado I, BonzonKulichenko E, et al. ALDH4A1 Is an Atherosclerosis Auto-Antigen Targeted by Protective Antibodies. Nature (2020) 589:1-6. doi: 10.1038/s41586-020-2993-2

13. Gisterå A, Hansson GK. The Immunology of Atherosclerosis. Nat Rev Nephrol (2017) 13:368-80. doi: 10.1038/nrneph.2017.51

14. Lim HY, Lim SY, Tan CK, Thiam CH, Goh CC, Carbajo D, et al. Hyaluronan Receptor LYVE-1-Expressing Macrophages Maintain Arterial Tone Through Hyaluronan-Mediated Regulation of Smooth Muscle Cell Collagen. Immunity (2018) 49:326-41.e7. doi: 10.1016/j.immuni.2018.06.008

15. Choi J-H, Do Y, Cheong C, Koh H, Boscardin SB, Oh Y-S, et al. Identification of Antigen-Presenting Dendritic Cells in Mouse Aorta and Cardiac Valves. J Exp Med (2009) 206:497-505. doi: 10.1084/jem.20082129

16. Williams JW, Zaitsev K, Kim K-W, Ivanov S, Saunders BT, Schrank PR, et al. Limited Proliferation Capacity of Aortic Intima Resident Macrophages Requires Monocyte Recruitment for Atherosclerotic Plaque Progression. Nat Immunol (2020) 21:1-11. doi: 10.1038/s41590-020-0768-4

17. Smith JD, Trogan E, Ginsberg M, Grigaux C, Tian J, Miyata M. Decreased Atherosclerosis in Mice Deficient in Both Macrophage Colony-Stimulating Factor (Op) and Apolipoprotein E. Proc Natl Acad Sci USA (1995) 92:8264-8. doi: 10.1073/pnas.92.18.8264

18. Qiao JH, Tripathi J, Mishra NK, Cai Y, Tripathi S, Wang XP, et al. Role of Macrophage Colony-Stimulating Factor in Atherosclerosis: Studies of Osteopetrotic Mice. Am J Pathol (1997) 150:1687-99.

19. Rajavashisth T, Qiao JH, Tripathi S, Tripathi J, Mishra N, Hua M, et al. Heterozygous Osteopetrotic (Op) Mutation Reduces Atherosclerosis in LDL Receptor- Deficient Mice. J Clin Invest (1998) 101:2702-10. doi: 10.1172/ jci119891

20. Villiers WJS de, Smith JD, Miyata M, Dansky HM, Darley E, Gordon S. Macrophage Phenotype in Mice Deficient in Both Macrophage-ColonyStimulating Factor (Op) and Apolipoprotein E. Arterioscler Thromb Vasc Biol (1998) 18:631-40. doi: 10.1161/01.atv.18.4.631

21. Stoneman V, Braganza D, Figg N, Mercer J, Lang R, Goddard M, et al. Monocyte/Macrophage Suppression in CD11b Diphtheria Toxin Receptor Transgenic Mice Differentially Affects Atherogenesis and Established Plaques. Circ Res (2007) 100:884-93. doi: 10.1161/01.res.0000260802.75766.00

22. Goldberg IJ, Sharma G, Fisher EA. Atherosclerosis: Making a U Turn. Annu Rev Med (2020) 71:191-201. doi: 10.1146/annurev-med-042418-011108 
23. Ajami B, Bennett JL, Krieger C, Tetzlaff W, Rossi FMV. Local Self-Renewal can Sustain CNS Microglia Maintenance and Function Throughout Adult Life. Nat Neurosci (2007) 10:1538-43. doi: 10.1038/nn2014

24. Yona S, Kim K-W, Wolf Y, Mildner A, Varol D, Breker M, et al. Fate Mapping Reveals Origins and Dynamics of Monocytes and Tissue Macrophages Under Homeostasis. Immunity (2012) 38:79-91. doi: 10.1016/j.immuni. 2012.12.001

25. Hashimoto D, Chow A, Noizat C, Teo P, Beasley MB, Leboeuf M, et al. TissueResident Macrophages Self-Maintain Locally Throughout Adult Life With Minimal Contribution From Circulating Monocytes. Immunity (2013) 38:792-804. doi: 10.1016/j.immuni.2013.04.004

26. Perdiguero EG, Klapproth K, Schulz C, Busch K, Azzoni E, Crozet L, et al. Tissue-Resident Macrophages Originate From Yolk-Sac-Derived ErythroMyeloid Progenitors. Nature (2014) 518:547-51. doi: 10.1038/nature13989

27. Stremmel C, Schuchert R, Wagner F, Thaler R, Weinberger T, Pick R, et al. Yolk Sac Macrophage Progenitors Traffic to the Embryo During Defined Stages of Development. Nat Commun (2018) 9:75. doi: 10.1038/s41467-01702492-2

28. Alliot F, Godin I, Pessac B. Microglia Derive From Progenitors, Originating From the Yolk Sac, and Which Proliferate in the Brain. Brain Res Dev Brain Res (1999) 117:145-52. doi: 10.1016/s0165-3806(99)00113-3

29. Ginhoux F, Greter M, Leboeuf M, Nandi S, See P, Gokhan S, et al. Fate Mapping Analysis Reveals That Adult Microglia Derive From Primitive Macrophages. Science (2010) 330:841-5. doi: 10.1126/science.1194637

30. Liu Z, Gu Y, Chakarov S, Bleriot C, Kwok I, Chen X, et al. Fate Mapping via Ms4a3-Expression History Traces Monocyte-Derived Cells. Cell (2019) 178:1509-25.e19. doi: 10.1016/j.cell.2019.08.009

31. Mass E. Delineating the Origins, Developmental Programs and Homeostatic Functions of Tissue-Resident Macrophages. Int Immunol (2018) 30:493-501. doi: 10.1093/intimm/dxy044

32. Mass E, Ballesteros I, Farlik M, Halbritter F, Gunther P, Crozet L, et al. Specification of Tissue-Resident Macrophages During Organogenesis. Science (2016) 353:aaf4238-aaf4238. doi: 10.1126/science.aaf4238

33. Jacome-Galarza CE, Percin GI, Muller JT, Mass E, Lazarov T, Eitler J, et al. Developmental Origin, Functional Maintenance and Genetic Rescue of Osteoclasts. Nature (2019) 568:541-5. doi: 10.1038/s41586-019-1105-7

34. Fantin A, Vieira JM, Gestri G, Denti L, Schwarz Q, Prykhozhij S, et al. Tissue Macrophages Act as Cellular Chaperones for Vascular Anastomosis Downstream of VEGF-Mediated Endothelial Tip Cell Induction. Blood (2010) 116:829-40. doi: 10.1182/blood-2009-12-257832

35. DeFalco T, Bhattacharya I, Williams AV, Sams DM, Capel B. Yolk-SacDerived Macrophages Regulate Fetal Testis Vascularization and Morphogenesis. Proc Natl Acad Sci USA (2014) 111:E2384-93. doi: 10.1073/ pnas.1400057111

36. Leid J, Carrelha J, Boukarabila H, Epelman S, Jacobsen SEW, Lavine KJ. Primitive Embryonic Macrophages Are Required for Coronary Development and Maturation. Circ Res (2016) 118:1498-511. doi: 10.1161/circresaha. 115.308270

37. Weinberger T, Esfandyari D, Messerer D, Percin G, Schleifer C, Thaler R, et al. Ontogeny of Arterial Macrophages Defines Their Functions in Homeostasis and Inflammation. Nat Commun (2020) 11:4549. doi: 10.1038/s41467-02018287-x

38. Jaitin DA, Adlung L, Thaiss CA, Weiner A, Li B, Descamps H, et al. LipidAssociated Macrophages Control Metabolic Homeostasis in a Trem2Dependent Manner. Cell (2019) 178:686-98.e14. doi: 10.1016/j.cell. 2019.05.054

39. Werner Y, Mass E, Kumar PA, Ulas T, Händler K, Horne A, et al. Cxcr4 Distinguishes HSC-Derived Monocytes From Microglia and Reveals Monocyte Immune Responses to Experimental Stroke. Nat Neurosci (2020) 23:351-62. doi: 10.1038/s41593-020-0585-y

40. Mould KJ, Barthel L, Mohning MP, Thomas SM, McCubbrey AL, Danhorn T, et al. Cell Origin Dictates Programming of Resident Versus Recruited Macrophages During Acute Lung Injury. Am J Resp Cell Mol Biol (2017) 57:294-306. doi: 10.1165/rcmb.2017-0061oc

41. Cronk JC, Filiano AJ, Louveau A, Marin I, Marsh R, Ji E, et al. Peripherally Derived Macrophages can Engraft the Brain Independent of Irradiation and Maintain an Identity Distinct From Microglia. J Exp Med (2018) 215:1627-47. doi: $10.1084 /$ jem.20180247
42. Kalluri AS, Vellarikkal SK, Edelman ER, Nguyen L, Subramanian A, Ellinor PT, et al. Single-Cell Analysis of the Normal Mouse Aorta Reveals Functionally Distinct Endothelial Cell Populations. Circulation (2019) 140:147-63. doi: 10.1161/circulationaha.118.038362

43. Gu W, Ni Z, Tan Y-Q, Deng J, Zhang S-J, Lv Z-C, et al. Adventitial Cell Atlas of Wt (Wild Type) and ApoE (Apolipoprotein E)-Deficient Mice Defined by Single-Cell RNA Sequencing. Arterioscler Thromb Vasc Biol (2019) 39:105571. doi: 10.1161/atvbaha.119.312399

44. Ensan S, Li A, Besla R, Degousee N, Cosme J, Roufaiel M, et al. Self-Renewing Resident Arterial Macrophages Arise From Embryonic CX3CR1(+) Precursors and Circulating Monocytes Immediately After Birth. Nat Immunol (2016) 17:159-68. doi: 10.1038/ni.3343

45. Percin GI, Eitler J, Kranz A, Fu J, Pollard JW, Naumann R, et al. CSF1R Regulates the Dendritic Cell Pool Size in Adult Mice via Embryo-Derived Tissue-Resident Macrophages. Nat Commun (2018) 9:5279. doi: 10.1038/ s41467-018-07685-x

46. Psaltis PJ, Harbuzariu A, Delacroix S, Witt TA, Holroyd EW, Spoon DB, et al. Identification of a Monocyte-Predisposed Hierarchy of Hematopoietic Progenitor Cells in the Adventitia of Postnatal Murine Aorta. Circulation (2012) 125:592-603. doi: 10.1161/circulationaha.111.059360

47. Psaltis PJ, Puranik AS, Spoon DB, Chue CD, Hoffman SJ, Witt TA, et al. Characterization of a Resident Population of Adventitial Macrophage Progenitor Cells in Postnatal Vasculature. Circ Res (2014) 115:364-75. doi: 10.1161/circresaha.115.303299

48. Lin J-D, Nishi H, Poles J, Niu X, Mccauley C, Rahman K, et al. Single-Cell Analysis of Fate-Mapped Macrophages Reveals Heterogeneity, Including Stem-Like Properties, During Atherosclerosis Progression and Regression. JCI Insight (2019) 4:e124574. doi: 10.1172/jci.insight.124574

49. Robbins CS, Hilgendorf I, Weber GF, Theurl I, Iwamoto Y, Figueiredo J-L, et al. Local Proliferation Dominates Lesional Macrophage Accumulation in Atherosclerosis. Nat Med (2013) 19:1166-72. doi: 10.1038/nm.3258

50. Dobnikar L, Taylor AL, Chappell J, Oldach P, Harman JL, Oerton E, et al. Disease-Relevant Transcriptional Signatures Identified in Individual Smooth Muscle Cells From Healthy Mouse Vessels. Nat Commun (2018) 9:4567. doi: 10.1038/s41467-018-06891-x

51. Shankman LS, Gomez D, Cherepanova OA, Salmon M, Alencar GF, Haskins RM, et al. KLF4-Dependent Phenotypic Modulation of Smooth Muscle Cells has a Key Role in Atherosclerotic Plaque Pathogenesis. Nat Med (2015) 21:628-37. doi: 10.1038/nm.3866

52. Pan H, Xue C, Auerbach BJ, Fan J, Bashore AC, Cui J, et al. Single-Cell Genomics Reveals a Novel Cell State During Smooth Muscle Cell Phenotypic Switching and Potential Therapeutic Targets for Atherosclerosis in Mouse and Human. Circulation (2020) 142:2060-75. doi: 10.1161/circulationaha.120.048378

53. Alencar GF, Owsiany KM KS, Sukhavasi K, Mocci G, Nguyen A, Williams CM, et al. The Stem Cell Pluripotency Genes Klf4 and Oct4 Regulate Complex SMC Phenotypic Changes Critical in Late-Stage Atherosclerotic Lesion Pathogenesis. Circulation (2020) 142:2045-59. doi: 10.1161/circulationaha.120.046672

54. Kudernatsch RF, Letsch A, Stachelscheid H, Volk H, Scheibenbogen C. Doublets Pretending to be CD34+ T Cells Despite Doublet Exclusion. Cytometry A (2013) 83A:173-6. doi: 10.1002/cyto.a.22247

55. Auffray C, Fogg D, Garfa M, Elain G, Join-Lambert O, Kayal S, et al. Monitoring of Blood Vessels and Tissues by a Population of Monocytes With Patrolling Behavior. Science (2007) 317:666-70. doi: 10.1126/ science. 1142883

56. Cros J, Cagnard N, Woollard K, Patey N, Zhang S-Y, Senechal B, et al. Human CD14dim Monocytes Patrol and Sense Nucleic Acids and Viruses via TLR7 and TLR8 Receptors. Immunity (2010) 33:375-86. doi: 10.1016/ j.immuni.2010.08.012

57. Carlin LM, Stamatiades EG, Auffray C, Hanna RN, Glover L, Vizcay-Barrena G, et al. Nr4a1-Dependent Ly6Clow Monocytes Monitor Endothelial Cells and Orchestrate Their Disposal. Cell (2013) 153:362-75. doi: 10.1016/ j.cell.2013.03.010

58. Marcovecchio PM, Thomas GD, Mikulski Z, Ehinger E, Mueller KAL, Blatchley A, et al. Scavenger Receptor CD36 Directs Nonclassical Monocyte Patrolling Along the Endothelium During Early Atherogenesis. Arterioscler Thromb Vasc Biol (2017) 37:2043-52. doi: 10.1161/atvbaha.117.309123

59. Jakubzick C, Gautier EL, Gibbings SL, Sojka DK, Schlitzer A, Johnson TE, et al. Minimal Differentiation of Classical Monocytes as They Survey Steady- 
State Tissues and Transport Antigen to Lymph Nodes. Immunity (2013) 39:599-610. doi: 10.1016/j.immuni.2013.08.007

60. Swirski FK, Nahrendorf M, Etzrodt M, Wildgruber M, Cortez-Retamozo V, Panizzi P, et al. Identification of Splenic Reservoir Monocytes and Their Deployment to Inflammatory Sites. Science (2009) 325:612-6. doi: 10.1126/ science. 1175202

61. Swirski FK, Pittet MJ, Kircher MF, Aikawa E, Jaffer FA, Libby P, et al. Monocyte Accumulation in Mouse Atherogenesis Is Progressive and Proportional to Extent of Disease. Proc Natl Acad Sci USA (2006) 103:10340-5. doi: 10.1073/pnas.0604260103

62. Roufaiel M, Gracey E, Siu A, Zhu S-N, Lau A, Ibrahim H, et al. CCL19-CCR7Dependent Reverse Transendothelial Migration of Myeloid Cells Clears Chlamydia Muridarum From the Arterial Intima. Nat Immunol (2016) 17:1263-72. doi: 10.1038/ni.3564

63. Drevets DA, Dillon MJ, Schawang JS, Rooijen Nv, Ehrchen J, Sunderkötter C, et al. The Ly-6chigh Monocyte Subpopulation Transports Listeria Monocytogenes Into the Brain During Systemic Infection of Mice. J Immunol (2004) 172:4418-24. doi: 10.4049/jimmunol.172.7.4418

64. Libby P, Egan D, Skarlatos S. Roles of Infectious Agents in Atherosclerosis and Restenosis: An Assessment of the Evidence and Need for Future Research. Circulation (1997) 96:4095-103. doi: 10.1161/01.cir.96.11.4095

65. Mulligan-Kehoe MJ, Simons M. Vasa Vasorum in Normal and Diseased Arteries. Circulation (2014) 129:2557-66. doi: 10.1161/circulationaha. 113.007189

66. Mills CD, Kincaid K, Alt JM, Heilman MJ, Hill AM. M-1/M-2 Macrophages and the Th1/Th2 Paradigm. J Immunol (2000) 164:6166-73. doi: 10.4049/ jimmunol.164.12.6166

67. Murray PJ, Allen JE, Biswas SK, Fisher EA, Gilroy DW, Goerdt S, et al. Macrophage Activation and Polarization: Nomenclature and Experimental Guidelines. Immunity (2014) 41:14-20. doi: 10.1016/j.immuni.2014.06.008

68. Nahrendorf M, Swirski FK. Abandoning M1/M2 for a Network Model of Macrophage Function. Circ Res (2016) 119:414-7. doi: 10.1161/circresaha. 116.309194

69. Mantovani A. Reflections on Immunological Nomenclature: In Praise of Imperfection. Nat Immunol (2016) 17:215-6. doi: 10.1038/ni.3354

70. Zernecke A, Winkels H, Cochain C, Williams JW, Wolf D, Soehnlein O, et al. Meta-Analysis of Leukocyte Diversity in Atherosclerotic Mouse Aortas. Circ Res (2020) 127:402-26. doi: 10.1161/circresaha.120.316903

71. Zernecke A, Erhard F, Weinberger T, Schulz C, Ley K, Saliba A-E, et al. Integrated scRNA-Seq Analysis Identifies Conserved Transcriptomic Features of Mononuclear Phagocytes in Mouse and Human Atherosclerosis. Biorxiv (2020). doi: 10.1101/2020.12.09.417535

72. Rantakari P, Patten DA, Valtonen J, Karikoski M, Gerke H, Dawes H, et al. Stabilin-1 Expression Defines a Subset of Macrophages That Mediate Tissue Homeostasis and Prevent Fibrosis in Chronic Liver Injury. Proc Natl Acad Sci USA (2016) 113:9298-303. doi: 10.1073/pnas.1604780113

73. Nepal S, Tiruppathi C, Tsukasaki Y, Farahany J, Mittal M, Rehman J, et al. STAT6 Induces Expression of Gas6 in Macrophages to Clear Apoptotic Neutrophils and Resolve Inflammation. Proc Natl Acad Sci USA (2019) 116:16513-8. doi: 10.1073/pnas.1821601116

74. Kojima Y, Volkmer J-P, McKenna K, Civelek M, Lusis AJ, Miller CL, et al. CD47-Blocking Antibodies Restore Phagocytosis and Prevent Atherosclerosis. Nature (2016) 536:86-90. doi: 10.1038/nature18935

75. Moore KJ, Sheedy FJ, Fisher EA. Macrophages in Atherosclerosis: A Dynamic Balance. Nat Rev Immunol (2013) 13:709-21. doi: 10.1038/nri3520

76. Doran AC, Yurdagul A, Tabas I. Efferocytosis in Health and Disease. Nat Rev Immunol (2020) 20:254-67. doi: 10.1038/s41577-019-0240-6

77. Allahverdian S, Chehroudi AC, McManus BM, Abraham T, Francis GA. Contribution of Intimal Smooth Muscle Cells to Cholesterol Accumulation and Macrophage-Like Cells in Human Atherosclerosis. Circulation (2014) 129:1551-9. doi: 10.1161/circulationaha.113.005015

78. Chèvre R, González-Granado JM, Megens RTA, Sreeramkumar V, SilvestreRoig C, Molina-Sánchez P, et al. High-Resolution Imaging of Intravascular Atherogenic Inflammation in Live Mice. Circ Res (2014) 114:770-9. doi: $10.1161 /$ circresaha.114.302590

79. Zhu S-N, Chen M, Jongstra-Bilen J, Cybulsky MI. GM-CSF Regulates Intimal Cell Proliferation in Nascent Atherosclerotic Lesions. J Exp Med (2009) 206:2141-9. doi: 10.1084/jem.20090866
80. Marchini T, Mitre LS, Wolf D. Inflammatory Cell Recruitment in Cardiovascular Disease. Front Cell Dev Biol (2021) 9:635527. doi: 10.3389/ fcell.2021.635527

81. Swirski FK, Libby P, Aikawa E, Alcaide P, Luscinskas FW, Weissleder R, et al. Ly-6Chi Monocytes Dominate Hypercholesterolemia-Associated Monocytosis and Give Rise to Macrophages in Atheromata. J Clin Invest (2007) 117:195-205. doi: 10.1172/jci29950

82. Tacke F, Alvarez D, Kaplan TJ, Jakubzick C, Spanbroek R, Llodra J, et al. Monocyte Subsets Differentially Employ CCR2, CCR5, and CX3CR1 to Accumulate Within Atherosclerotic Plaques. J Clin Invest (2007) 117:18594. doi: $10.1172 /$ jci28549

83. Combadiere C, Potteaux S, Rodero M, Simon T, Pezard A, Esposito B, et al. Combined Inhibition of CCL2, CX3CR1, and CCR5 Abrogates Ly6Chi and Ly6Clo Monocytosis and Almost Abolishes Atherosclerosis in Hypercholesterolemic Mice. Circulation (2008) 117:1649-57. doi: 10.1161/ circulationaha.107.745091

84. Saederup N, Chan L, Lira SA, Charo IF. Fractalkine Deficiency Markedly Reduces Macrophage Accumulation and Atherosclerotic Lesion Formation in CCR2-/Mice: Evidence for Independent Chemokine Functions in Atherogenesis. Circulation (2008) 117:1642-8. doi: 10.1161/circulationaha.107.743872

85. Eriksson EE. Intravital Microscopy on Atherosclerosis in Apolipoprotein EDeficient Mice Establishes Microvessels as Major Entry Pathways for Leukocytes to Advanced Lesions. Circulation (2011) 124:2129-38. doi: 10.1161/circulationaha.111.030627

86. McNeill E, Iqbal AJ, Jones D, Patel J, Coutinho P, Taylor L, et al. Tracking Monocyte Recruitment and Macrophage Accumulation in Atherosclerotic Plaque Progression Using a Novel Hcd68gfp/ApoE-/- Reporter Mouse-Brief Report. Arterioscler Thromb Vasc Biol (2017) 37:258-63. doi: 10.1161/ atvbaha.116.308367

87. Williams JW, Martel C, Potteaux S, Esaulova E, Ingersoll MA, Elvington A, et al. Limited Macrophage Positional Dynamics in Progressing or Regressing Murine Atherosclerotic Plaques. Arterioscler Thromb Vasc Biol (2018) 38:1702-10. doi: 10.1161/atvbaha.118.311319

88. Yvan-Charvet L, Pagler T, Gautier EL, Avagyan S, Siry RL, Han S, et al. ATPBinding Cassette Transporters and HDL Suppress Hematopoietic Stem Cell Proliferation. Science (2010) 328:1689-93. doi: 10.1126/science.1189731

89. Murphy AJ, Akhtari M, Tolani S, Pagler T, Bijl N, Kuo C-L, et al. ApoE Regulates Hematopoietic Stem Cell Proliferation, Monocytosis, and Monocyte Accumulation in Atherosclerotic Lesions in Mice. J Clin Invest (2011) 121:4138-49. doi: 10.1172/jci57559

90. Hermetet F, Buffière A, Aznague A, Barros J-PP de, Bastie J-N, Delva L, et al. High-Fat Diet Disturbs Lipid Raft/TGF- $\beta$ Signaling-Mediated Maintenance of Hematopoietic Stem Cells in Mouse Bone Marrow. Nat Commun (2019) 10:523. doi: 10.1038/s41467-018-08228-0

91. Robbins CS, Chudnovskiy A, Rauch PJ, Figueiredo J-L, Iwamoto Y, Gorbatov R, et al. Extramedullary Hematopoiesis Generates Ly-6chigh Monocytes That Infiltrate Atherosclerotic Lesions. Circulation (2012) 125:364-74. doi: 10.1161/circulationaha.111.061986

92. Nagareddy PR, Murphy AJ, Stirzaker RA, Hu Y, Yu S, Miller RG, et al. Hyperglycemia Promotes Myelopoiesis and Impairs the Resolution of Atherosclerosis. Cell Metab (2013) 17:695-708. doi: 10.1016/j.cmet.2013. 04.001

93. McAlpine CS, Kiss MG, Rattik S, He S, Vassalli A, Valet C, et al. Sleep Modulates Haematopoiesis and Protects Against Atherosclerosis. Nature (2019) 566:383-7. doi: 10.1038/s41586-019-0948-2

94. Heidt T, Sager HB, Courties G, Dutta P, Iwamoto Y, Zaltsman A, et al. Chronic Variable Stress Activates Hematopoietic Stem Cells. Nat Med (2014) 20:754-8. doi: 10.1038/nm.3589

95. Shirai T, Nazarewicz RR, Wallis BB, Yanes RE, Watanabe R, Hilhorst M, et al. The Glycolytic Enzyme PKM2 Bridges Metabolic and Inflammatory Dysfunction in Coronary Artery Disease. J Exp Med (2016) 213:337-54. doi: $10.1084 /$ jem. 20150900

96. Devêvre EF, Renovato-Martins M, Clément K, Sautès-Fridman C, Cremer I, Poitou C. Profiling of the Three Circulating Monocyte Subpopulations in Human Obesity. J Immunol (2015) 194:3917-23. doi: 10.4049/jimmunol. 1402655

97. Lian Z, Perrard XD, Peng X, Raya JL, Hernandez AA, Johnson CG, et al. Replacing Saturated Fat With Unsaturated Fat in Western Diet Reduces 
Foamy Monocytes and Atherosclerosis in Male Ldlr-/- Mice. Arterioscler Thromb Vasc Biol (2018) 40:72-85. doi: 10.1161/atvbaha.119.313078

98. Wolf AA, Yáñez A, Barman PK, Goodridge HS. The Ontogeny of Monocyte Subsets. Front Immunol (2019) 10:1642. doi: 10.3389/fimmu.2019.01642

99. Dal-Secco D, Wang J, Zeng Z, Kolaczkowska E, Wong CHY, Petri B, et al. A Dynamic Spectrum of Monocytes Arising From the in Situ Reprogramming of CCR2+ Monocytes at a Site of Sterile injury In Situ Monocyte Conversion in Sterile Injury. J Exp Med (2015) 212:447-56. doi: 10.1084/jem.20141539

100. Wu H, Gower RM, Wang H, Perrard X-YD, Ma R, Bullard DC, et al. Functional Role of CD11c+ Monocytes in Atherogenesis Associated With Hypercholesterolemia. Circulation (2009) 119:2708-17. doi: 10.1161/ circulationaha.108.823740

101. Xu L, Perrard XD, Perrard JL, Yang D, Xiao X, Teng B-B, et al. Foamy Monocytes Form Early and Contribute to Nascent Atherosclerosis in Mice With Hypercholesterolemia. Arterioscler Thromb Vasc Biol (2018) 35:178797. doi: 10.1161/atvbaha.115.305609

102. Quintar A, McArdle S, Wolf D, Marki A, Ehinger E, Vassallo M, et al. Endothelial Protective Monocyte Patrolling in Large Arteries Intensified by Western Diet and Atherosclerosis. Circ Res (2017) 120:1789-99. doi: 10.1161/circresaha.117.310739

103. Platt AM, Bain CC, Bordon Y, Sester DP. Mowat AMcI. An Independent Subset of TLR Expressing CCR2-Dependent Macrophages Promotes Colonic Inflammation. J Immunol (2010) 184:6843-54. doi: 10.4049/jimmunol. 0903987

104. Zigmond E, Varol C, Farache J, Elmaliah E, Satpathy AT, Friedlander G, et al. Ly6Chi Monocytes in the Inflamed Colon Give Rise to Proinflammatory Effector Cells and Migratory Antigen-Presenting Cells. Immunity (2012) 37:1076-90. doi: 10.1016/j.immuni.2012.08.026

105. Fife BT, Huffnagle GB, Kuziel WA, Karpus WJ. Cc Chemokine Receptor 2 Is Critical for Induction of Experimental Autoimmune Encephalomyelitis. J Exp Med (2000) 192:899-906. doi: 10.1084/jem.192.6.899

106. Yamasaki R, Lu H, Butovsky O, Ohno N, Rietsch AM, Cialic R, et al. Differential Roles of Microglia and Monocytes in the Inflamed Central Nervous System. J Exp Med (2014) 211:1533-49. doi: 10.1084/jem.20132477

107. Guo J, Waard V, Eck MV, Hildebrand RB, Wanrooij EJAv, Kuiper J, et al. Repopulation of Apolipoprotein E Knockout Mice With CCR2-Deficient Bone Marrow Progenitor Cells Does Not Inhibit Ongoing Atherosclerotic Lesion Development. Arterioscler Thromb Vasc Biol (2005) 25:1014-9. doi: 10.1161/01.atv.0000163181.40896.42

108. Aiello RJ, Perry BD, Bourassa P-A, Robertson A, Weng W, Knight DR, et al. CCR2 Receptor Blockade Alters Blood Monocyte Subpopulations But Does Not Affect Atherosclerotic Lesions in Apoe-/- Mice. Atherosclerosis (2010) 208:370-5. doi: 10.1016/j.atherosclerosis.2009.08.017

109. Ye D, Zhao Y, Hildebrand RB, Singaraja RR, Hayden MR, Berkel TJCV, et al. The Dynamics of Macrophage Infiltration Into the Arterial Wall During Atherosclerotic Lesion Development in Low-Density Lipoprotein Receptor Knockout Mice. Am J Pathol (2011) 178:413-22. doi: 10.1016/j.ajpath.2010. 11.007

110. McArdle S, Buscher K, Ghosheh Y, Pramod AB, Miller J, Winkels H, et al. Migratory and Dancing Macrophage Subsets in Atherosclerotic Lesions. Circ Res (2019) 125:1038-51. doi: 10.1161/circresaha.119.315175

111. Blériot C, Dupuis T, Jouvion G, Eberl G, Disson O, Lecuit M. Liver-Resident Macrophage Necroptosis Orchestrates Type 1 Microbicidal Inflammation and Type-2-Mediated Tissue Repair During Bacterial Infection. Immunity (2015) 42:145-58. doi: 10.1016/j.immuni.2014.12.020

112. Ajami B, Bennett JL, Krieger C, McNagny KM, Rossi FMV. Infiltrating Monocytes Trigger EAE Progression, But do Not Contribute to the Resident Microglia Pool. Nat Neurosci (2011) 14:1142-9. doi: 10.1038/nn.2887

113. Guilliams M, Svedberg FR. Does Tissue Imprinting Restrict Macrophage Plasticity? Nat Immunol (2021) 22:1-10. doi: 10.1038/s41590-020-00849-2

114. Bellingan GJ, Caldwell H, Howie SE, Dransfield I, Haslett C. In Vivo Fate of the Inflammatory Macrophage During the Resolution of Inflammation: Inflammatory Macrophages Do Not Die Locally, But Emigrate to the Draining Lymph Nodes. J Immunol (1996) 157:2577-85.

115. Gils JMv, Derby MC, Fernandes LR, Ramkhelawon B, Ray TD, Rayner KJ, et al. The Neuroimmune Guidance Cue Netrin-1 Promotes Atherosclerosis by Inhibiting the Emigration of Macrophages From Plaques. Nat Immunol (2012) 13:136-43. doi: 10.1038/ni.2205
116. Wanschel A, Seibert T, Hewing B, Ramkhelawon B, Ray TD, Gils JMv, et al. Neuroimmune Guidance Cue Semaphorin 3e Is Expressed in Atherosclerotic Plaques and Regulates Macrophage Retention. Arterioscler Thromb Vasc Biol (2018) 33:886-93. doi: 10.1161/atvbaha.112.300941

117. Llodrá J, Angeli V, Liu J, Trogan E, Fisher EA, Randolph GJ. Emigration of Monocyte-Derived Cells From Atherosclerotic Lesions Characterizes Regressive, But Not Progressive, Plaques. Proc Natl Acad Sci USA (2004) 101:11779-84. doi: 10.1073/pnas.0403259101

118. Nagao T, Qin C, Grosheva I, Maxfield FR, Pierini LM. Elevated Cholesterol Levels in the Plasma Membranes of Macrophages Inhibit Migration by Disrupting RhoA Regulation. Arterioscler Thromb Vasc Biol (2007) 27:1596602. doi: 10.1161/atvbaha.107.145086

119. McArdle S, Chodaczek G, Ray N, Ley K. Intravital Live Cell Triggered Imaging System Reveals Monocyte Patrolling and Macrophage Migration in Atherosclerotic Arteries. J BioMed Opt (2015) 20:026005-5. doi: 10.1117/ 1.jbo.20.2.026005

120. Kim K, Shim D, Lee JS, Zaitsev K, Williams JW, Kim K-W, et al. Transcriptome Analysis Reveals Nonfoamy Rather Than Foamy Plaque Macrophages Are Proinflammatory in Atherosclerotic Murine Models. Circ Res (2018) 123:1127-42. doi: 10.1161/circresaha.118.312804

121. Cochain C, Vafadarnejad E, Arampatzi P, Pelisek J, Winkels H, Ley K, et al. Single-Cell RNA-Seq Reveals the Transcriptional Landscape and Heterogeneity of Aortic Macrophages in Murine Atherosclerosis. Circ Res (2018) 122:1661-74. doi: 10.1161/circresaha.117.312509

122. Cochain C, Saliba A-E, Zernecke A. Letter by Cochain et al. Regarding Article, "Transcriptome Analysis Reveals Nonfoamy Rather Than Foamy Plaque Macrophages Are Proinflammatory in Atherosclerotic Murine Models." Circ Res (2018) 123:e48-9. doi: 10.1161/circresaha.118.314120

123. Bailey CC, DeVaux LB, Farzan M. The Triggering Receptor Expressed on Myeloid Cells 2 Binds Apolipoprotein E. J Biol Chem (2015) 290:26033-42. doi: $10.1074 / j b c . m 115.677286$

124. Turnbull IR, Gilfillan S, Cella M, Aoshi T, Miller M, Piccio L, et al. Cutting Edge: TREM-2 Attenuates Macrophage Activation. J Immunol (2006) 177:3520-4. doi: 10.4049/jimmunol.177.6.3520

125. Keren-Shaul H, Spinrad A, Weiner A, Matcovitch-Natan O, Dvir-Szternfeld R, Ulland TK, et al. A Unique Microglia Type Associated With Restricting Development of Alzheimer's Disease. Cell (2017) 169:1276-90.e17. doi: 10.1016/j.cell.2017.05.018

126. Chen H-J, Tas SW, de Winther MPJ. Type-I Interferons in Atherosclerosis. J Exp Med (2019) 217:e20190459. doi: 10.1084/jem.20190459

127. Wang J, Kubes P. A Reservoir of Mature Cavity Macrophages That Can Rapidly Invade Visceral Organs to Affect Tissue Repair. Cell (2016) 165:66878. doi: 10.1016/j.cell.2016.03.009

128. Deniset JF, Belke D, Lee W-Y, Jorch SK, Deppermann C, Hassanabad AF, et al. Gata6+ Pericardial Cavity Macrophages Relocate to the Injured Heart and Prevent Cardiac Fibrosis. Immunity (2019) 51:131-40.e5. doi: 10.1016/ j.immuni.2019.06.010

129. Zindel J, Peiseler M, Hossain M, Deppermann C, Lee WY, Haenni B, et al. Primordial GATA6 Macrophages Function as Extravascular Platelets in Sterile Injury. Science (2021) 371:eabe0595. doi: 10.1126/science.abe0595

130. Josefs T, Basu D, Vaisar T, Arets B, Kanter JE, Huggins L-A, et al. Atherosclerosis Regression and Cholesterol Efflux in Hypertriglyceridemic Mice. Circ Res (2021) 128:690-705. doi: 10.1161/circresaha.120.317458

131. Burke AC, Huff MW. Regression of Atherosclerosis. Curr Opin Lipidol (2018) 29:87-94. doi: 10.1097/mol.0000000000000493

132. Lieu HD, Withycombe SK, Walker Q, Rong JX, Walzem RL, Wong JS, et al. Eliminating Atherogenesis in Mice by Switching Off Hepatic Lipoprotein Secretion. Circulation (2003) 107:1315-21. doi: 10.1161/01.cir.0000054781.50889.0c

133. Reis ED, Li J, Fayad ZA, Rong JX, Hansoty D, Aguinaldo J-G, et al. Dramatic Remodeling of Advanced Atherosclerotic Plaques of the Apolipoprotein Edeficient Mouse in a Novel Transplantation Model. J Vasc Surg (2001) 34:541-2A. doi: 10.1067/mva.2001.115963

134. Craeyveld EV, Gordts SC, Nefyodova E, Jacobs F, Geest BD. Regression and Stabilization of Advanced Murine Atherosclerotic Lesions: A Comparison of LDL Lowering and HDL Raising Gene Transfer Strategies. J Mol Med Berl (2011) 89:555-67. doi: 10.1007/s00109-011-0722-x

135. Peled M, Nishi H, Weinstock A, Barrett TJ, Zhou F, Quezada A. Fisher EA. A Wild-Type Mouse-Based Model for the Regression of Inflammation in 
Atherosclerosis. PLoS One (2017) 12:e0173975. doi: 10.1371/journal. pone. 0173975

136. Basu D, Hu Y, Huggins L-A, Mullick AE, Graham MJ, Wietecha T, et al. Novel Reversible Model of Atherosclerosis and Regression Using Oligonucleotide Regulation of the LDL Receptor. Circ Res (2018) 122:5607. doi: $10.1161 /$ circresaha.117.311361

137. Zadelaar S, Kleemann R, Verschuren L, Weij J deV-Vd, Hoorn Jvd, Princen HM, et al. Mouse Models for Atherosclerosis and Pharmaceutical Modifiers. Arterioscler Thromb Vasc Biol (2007) 27:1706-21. doi: 10.1161/ atvbaha.107.142570

138. Tsukamoto K, Tangirala R, Chun SH, Pure E, Rader DJ. Rapid Regression of Atherosclerosis Induced by Liver-Directed Gene Transfer of ApoE in ApoEDeficient Mice. Arterioscler Thromb Vasc Biol (1999) 19:2162-70. doi: 10.1161/01.atv.19.9.2162

139. Graham MJ, Lee RG, Brandt TA, Tai L-J, Fu W, Peralta R, et al. Cardiovascular and Metabolic Effects of ANGPTL3Antisense Oligonucleotides. N Engl J Med (2017) 377:222-32. doi: 10.1056/ nejmoa1701329

140. Witztum JL, Gaudet D, Freedman SD, Alexander VJ, Digenio A, Williams KR, et al. Volanesorsen and Triglyceride Levels in Familial Chylomicronemia Syndrome. N Engl J Med (2019) 381:531-42. doi: 10.1056/nejmoa1715944

141. Trogan E, Fayad ZA, Itskovich VV, Aguinaldo J-GS, Mani V, Fallon JT, et al. Serial Studies of Mouse Atherosclerosis by In Vivo Magnetic Resonance Imaging Detect Lesion Regression After Correction of Dyslipidemia. Arterioscler Thromb Vasc Biol (2004) 24:1714-9. doi: 10.1161/01.atv. 0000139313.69015.1c

142. Feig JE, Pineda-Torra I, Sanson M, Bradley MN, Vengrenyuk Y, Bogunovic D, et al. LXR Promotes the Maximal Egress of Monocyte-Derived Cells From Mouse Aortic Plaques During Atherosclerosis Regression. J Clin Invest (2010) 120:4415-24. doi: 10.1172/jci38911

143. Feig JE, Parathath S, Rong JX, Mick SL, Vengrenyuk Y, Grauer L, et al. Reversal of Hyperlipidemia With a Genetic Switch Favorably Affects the Content and Inflammatory State of Macrophages in Atherosclerotic Plaques. Circulation (2011) 123:989-98. doi: 10.1161/circulationaha.110.984146

144. Trogan E, Feig JE, Dogan S, Rothblat GH, Angeli V, Tacke F, et al. Gene Expression Changes in Foam Cells and the Role of Chemokine Receptor CCR7 During Atherosclerosis Regression in ApoE-Deficient Mice. Proc Natl Acad Sci USA (2006) 103:3781-6. doi: 10.1073/pnas.0511043103

145. Härdtner C, Kornemann J, Krebs K, Ehlert CA, Jander A, Zou J, et al. Inhibition of Macrophage Proliferation Dominates Plaque Regression in Response to Cholesterol Lowering. Basic Res Cardiol (2020) 115:78. doi: 10.1007/s00395-020-00838-4

146. Potteaux S, Gautier EL, Hutchison SB, Rooijen Nv, Rader DJ, Thomas MJ, et al. Suppressed Monocyte Recruitment Drives Macrophage Removal From Atherosclerotic Plaques of Apoe-/- Mice During Disease Regression. J Clin Invest (2011) 121:2025-36. doi: 10.1172/jci43802

147. Pagler TA, Wang M, Mondal M, Murphy AJ, Westerterp M, Moore KJ, et al. Deletion of ABCA1 and ABCG1 Impairs Macrophage Migration Because of Increased Rac1 Signaling. Circ Res (2011) 108:194-200. doi: 10.1161/ circresaha.110.228619

148. Feig JE, Shang Y, Rotllan N, Vengrenyuk Y, Wu C, Shamir R, et al. Statins Promote the Regression of Atherosclerosis via Activation of the CCR7Dependent Emigration Pathway in Macrophages. PLoS One (2011) 6:e28534. doi: 10.1371/journal.pone.0028534

149. Sharma M, Schlegel MP, Afonso MS, Brown EJ, Rahman K, Weinstock A, et al. Regulatory T Cells License Macrophage Pro-Resolving Functions During Atherosclerosis Regression. Circ Res (2020) 127:335-53. doi: 10.1161/circresaha.119.316461

150. Mueller PA, Zhu L, Tavori H, Huynh K, Giunzioni I, Stafford JM, et al. Deletion of Macrophage Low-Density Lipoprotein Receptor-Related Protein 1 (LRP1) Accelerates Atherosclerosis Regression and Increases CCR7 Expression in Plaque Macrophages. Circulation (2018) 138:1850-63. doi: $10.1161 /$ circulationaha.117.031702

151. Fullerton JN, Gilroy DW. Resolution of Inflammation: A New Therapeutic Frontier. Nat Rev Drug Discov (2016) 15:551-67. doi: 10.1038/nrd.2016.39

152. Gautier EL, Ivanov S, Lesnik P, Randolph GJ. Local Apoptosis Mediates Clearance of Macrophages From Resolving Inflammation in Mice. Blood (2013) 122:2714-22. doi: 10.1182/blood-2013-01-478206
153. Rajavashisth TB, Andalibi A, Territo MC, Berliner JA, Navab M, Fogelman $\mathrm{AM}$, et al. Induction of Endothelial Cell Expression of Granulocyte and Macrophage Colony-Stimulating Factors by Modified Low-Density Lipoproteins. Nature (1990) 344:254-7. doi: 10.1038/344254a0

154. Sinha SK, Miikeda A, Fouladian Z, Mehrabian M, Edillor C, Shih D, et al. Local M-CSF (Macrophage Colony-Stimulating Factor) Expression Regulates Macrophage Proliferation and Apoptosis in Atherosclerosis. Arterioscler Thromb Vasc Biol (2020) 41:220-33. doi: 10.1161/atvbaha.120.315255

155. Baba O, Huang L-H, Elvington A, Szpakowska M, Sultan D, Heo GS, et al. CXCR4-Binding Positron Emission Tomography Tracers Link Monocyte Recruitment and Endothelial Injury in Murine Atherosclerosis. Arterioscler Thromb Vasc Biol (2021) 41:822-36. doi: 10.1161/atvbaha.120.315053

156. Nahrendorf M, Swirski FK, Aikawa E, Stangenberg L, Wurdinger T, Figueiredo J-L, et al. The Healing Myocardium Sequentially Mobilizes Two Monocyte Subsets With Divergent and Complementary Functions. J Exp Med (2007) 204:3037-47. doi: 10.1084/jem.20070885

157. Hilgendorf I, Gerhardt L, Tan TC, Winter C, Holderried TAW, Chousterman BG, et al. Ly-6chigh Monocytes Depend on Nr4al to Balance Both Inflammatory and Reparative Phases in the Infarcted Myocardium. Circ Res (2014) 114:161122. doi: $10.1161 /$ circresaha.114.303204

158. Duffield JS, Forbes SJ, Constandinou CM, Clay S, Partolina M, Vuthoori S, et al. Selective Depletion of Macrophages Reveals Distinct, Opposing Roles During Liver Injury and Repair. J Clin Invest (2005) 115:56-65. doi: 10.1172/ jci200522675

159. Goren I, Allmann N, Yogev N, Schürmann C, Linke A, Holdener M, et al. A Transgenic Mouse Model of Inducible Macrophage Depletion: Effects of Diphtheria Toxin-Driven Lysozyme M-Specific Cell Lineage Ablation on Wound Inflammatory, Angiogenic, and Contractive Processes. Am J Pathol (2009) 175:132-47. doi: 10.2353/ajpath.2009.081002

160. Lucas T, Waisman A, Ranjan R, Roes J, Krieg T, Müller W, et al. Differential Roles of Macrophages in Diverse Phases of Skin Repair. J Immunol (2010) 184:3964-77. doi: 10.4049/jimmunol.0903356

161. Rahman K, Vengrenyuk Y, Ramsey SA, Vila NR, Girgis NM, Liu J, et al. Inflammatory Ly6Chi Monocytes and Their Conversion to M2 Macrophages Drive Atherosclerosis Regression. J Clin Invest (2017) 127:2904-15. doi: $10.1172 /$ jci75005

162. Thomas GD, Hanna RN, Vasudevan NT, Hamers AA, Romanoski CE, McArdle S, et al. Deleting an Nr4al Super-Enhancer Subdomain Ablates Ly6C(low) Monocytes While Preserving Macrophage Gene Function. Immunity (2016) 45:975-87. doi: 10.1016/j.immuni.2016.10.011

163. Ikeda N, Asano K, Kikuchi K, Uchida Y, Ikegami H, Takagi R, et al. Emergence of Immunoregulatory Ym1+Ly6Chi Monocytes During Recovery Phase of Tissue Injury. Sci Immunol (2018) 3:eaat0207. doi: 10.1126/sciimmunol.aat0207

164. Van den Bossche J, Baardman J, Otto NA, van der Velden S, Neele AE, van den Berg SM, et al. Mitochondrial Dysfunction Prevents Repolarization of Inflammatory Macrophages. Cell Rep (2016) 17:684-96. doi: 10.1016/ j.celrep.2016.09.008

165. Khallou-Laschet J, Varthaman A, Fornasa G, Compain C, Gaston A-T, Clement M, et al. Macrophage Plasticity in Experimental Atherosclerosis. PLoS One (2010) 5:e8852. doi: 10.1371/journal.pone.0008852

166. Arnold L, Henry A, Poron F, Baba-Amer Y, Rooijen Nv, Plonquet A, et al. Inflammatory Monocytes Recruited After Skeletal Muscle Injury Switch Into Antiinflammatory Macrophages to Support Myogenesis. J Exp Med (2007) 204:1057-69. doi: 10.1084/jem.20070075

167. Locatelli G, Theodorou D, Kendirli A, Jordão MJC, Staszewski O, Phulphagar K, et al. Mononuclear Phagocytes Locally Specify and Adapt Their Phenotype in a Multiple Sclerosis Model. Nat Neurosci (2018) 21:1196-208. doi: 10.1038/s41593-018-0212-3

168. Lavine KJ, Epelman S, Uchida K, Weber KJ, Nichols CG, Schilling JD, et al. Distinct Macrophage Lineages Contribute to Disparate Patterns of Cardiac Recovery and Remodeling in the Neonatal and Adult Heart. Proc Natl Acad Sci USA (2014) 111:16029-34. doi: 10.1073/pnas.1406508111

169. Epelman S, Lavine KJ, Beaudin AE, Sojka DK, Carrero JA, Calderon B, et al. Embryonic and Adult-Derived Resident Cardiac Macrophages Are Maintained Through Distinct Mechanisms at Steady State and During Inflammation. Immunity (2014) 40:91-104. doi: 10.1016/j.immuni.2013. 11.019 
170. Tavian M, Peault B. Embryonic Development of the Human Hematopoietic System. Int J Dev Biol (2003) 49:243-50. doi: 10.1387/ijdb.041957mt

171. Godin I, Cumano A. The Hare and the Tortoise: An Embryonic Haematopoietic Race. Nat Rev Immunol (2002) 2:593-604. doi: 10.1038/ nri857

172. Enzan H. Electron Microscopic Studies of Macrophages in Early Human Yolk Sacs. Acta Pathol Jpn (1986) 36:49-64. doi: 10.1111/j.1440-1827. 1986.tb01460.x

173. Migliaccio G, Migliaccio AR, Petti S, Mavilio F, Russo G, Lazzaro D, et al. Human Embryonic Hemopoiesis. Kinetics of Progenitors and Precursors Underlying the Yolk Sac--Liver Transition. J Clin Invest (1986) 78:51-60. doi: $10.1172 /$ jci1 12572

174. Bian Z, Gong Y, Huang T, Lee CZW, Bian L, Bai Z, et al. Deciphering Human Macrophage Development at Single-Cell Resolution. Nature (2020) 582:571-6. doi: 10.1038/s41586-020-2316-7

175. Doebel T, Voisin B, Nagao K. Langerhans Cells - The Macrophage in Dendritic Cell Clothing. Trends Immunol (2017) 38:817-28. doi: 10.1016/ j.it.2017.06.008

176. Bigley V, Haniffa M, Doulatov S, Wang X-N, Dickinson R, McGovern N, et al. The Human Syndrome of Dendritic Cell, Monocyte, B and NK Lymphoid Deficiency. J Exp Med (2011) 208:227-34. doi: 10.1084/ jem.20101459

177. McGovern N, Schlitzer A, Gunawan M, Jardine L, Shin A, Poyner E, et al. Human Dermal CD14+ Cells Are a Transient Population of MonocyteDerived Macrophages. Immunity (2014) 41:465-77. doi: 10.1016/j.immuni. 2014.08.006

178. Hu Z, Liu W, Hua X, Chen X, Chang Y, Hu Y, et al. Single-Cell Transcriptomic Atlas of Different Human Cardiac Arteries Identifies Cell Types Associated With Vascular Physiology. Arterioscler Thromb Vasc Biol (2021) 41:1408-27. doi: 10.1161/atvbaha.120.315373

179. Li Y, Ren P, Dawson A, Vasquez HG, Ageedi W, Zhang C, et al. Single-Cell Transcriptome Analysis Reveals Dynamic Cell Populations and Differential Gene Expression Patterns in Control and Aneurysmal Human Aortic Tissue. Circulation (2020) 142:1374-88. doi: 10.1161/circulationaha.120.046528

180. Waltner-Romen M, Falkensammer G, Rabl W, Wick G. A Previously Unrecognized Site of Local Accumulation of Mononuclear Cells. J Histochem Cytochem (1998) 46:1347-50. doi: 10.1177/002215549804601202

181. Stary HC, Blankenhorn DH, Chandler AB, Glagov S, Insull W, Richardson $M$, et al. A Definition of the Intima of Human Arteries and of Its Atherosclerosis-Prone Regions. A Report From the Committee on Vascular Lesions of the Council on Arteriosclerosis, American Heart Association. Circulation (1992) 85:391-405. doi: 10.1161/01.cir.85.1.391

182. Wick G, Romen M, Amberger A, Metzler B, Mayr M, Falkensammer G, et al. Atherosclerosis, Autoimmunity, and Vascular-Associated Lymphoid Tissue. FASEB J (1997) 11:1199-207. doi: 10.1096/fasebj.11.13.9367355

183. Bobryshev YV, Lord RS. Ultrastructural Recognition of Cells With Dendritic Cell Morphology in Human Aortic Intima. Contacting Interactions of Vascular Dendritic Cells in Athero-Resistant and Athero-Prone Areas of the Normal Aorta. Arch Histol Cytol (1995) 58:307-22. doi: 10.1679/ aohc.58.307

184. Millonig G, Malcom GT, Wick G. Early Inflammatory-Immunological Lesions in Juvenile Atherosclerosis From the Pathobiological Determinants of Atherosclerosis in Youth (PDAY)-Study. Atherosclerosis (2002) 160:4418. doi: 10.1016/s0021-9150(01)00596-2

185. Dutertre C-A, Clement M, Morvan M, Schäkel K, Castier Y, Alsac J-M, et al. Deciphering the Stromal and Hematopoietic Cell Network of the Adventitia From Non-Aneurysmal and Aneurysmal Human Aorta. PLoS One (2014) 9: e89983. doi: 10.1371/journal.pone.0089983

186. Kortelainen M-L, Porvari K. Adventitial Macrophage and Lymphocyte Accumulation Accompanying Early Stages of Human Coronary Atherogenesis. Cardiovasc Pathol (2014) 23:193-7. doi: 10.1016/j.carpath. 2014.03.001

187. Watanabe M, Sangawa A, Sasaki Y, Yamashita M, Tanaka-Shintani M, Shintaku M, et al. Distribution of Inflammatory Cells in Adventitia Changed With Advancing Atherosclerosis of Human Coronary Artery. J Atheroscler Thromb (2007) 14:325-31. doi: 10.5551/jat.e489

188. Kanitakis J, Petruzzo P, Dubernard J-M. Turnover of Epidermal Langerhans' Cells. N Engl J Med (2004) 351:2661-2. doi: 10.1056/nejm200412163512523
189. Kanitakis J, Morelon E, Petruzzo P, Badet L, Dubernard J. Self-Renewal Capacity of Human Epidermal Langerhans Cells: Observations Made on a Composite Tissue Allograft. Exp Dermatol (2011) 20:145-6. doi: 10.1111/ j.1600-0625.2010.01146.x

190. Bajpai G, Schneider C, Wong N, Bredemeyer A, Hulsmans M, Nahrendorf $\mathrm{M}$, et al. The Human Heart Contains Distinct Macrophage Subsets With Divergent Origins and Functions. Nat Med (2018) 24:1234-45. doi: 10.1038/ s41591-018-0059-x

191. Pryshchep O, Ma-Krupa W, Younge BR, Goronzy JJ, Weyand CM. VesselSpecific Toll-Like Receptor Profiles in Human Medium and Large Arteries. Circulation (2008) 118:1276-84. doi: 10.1161/circulationaha.108.789172

192. Iwata H, Manabe I, Fujiu K, Yamamoto T, Takeda N, Eguchi K, et al. Bone Marrow-Derived Cells Contribute to Vascular Inflammation But Do Not Differentiate Into Smooth Muscle Cell Lineages. Circulation (2010) 122:2048-57. doi: 10.1161/circulationaha.110.965202

193. Caplice NM, Bunch TJ, Stalboerger PG, Wang S, Simper D, Miller DV, et al. Smooth Muscle Cells in Human Coronary Atherosclerosis can Originate From Cells Administered at Marrow Transplantation. Proc Natl Acad Sci USA (2003) 100:4754-9. doi: 10.1073/pnas.0730743100

194. Martin K, Weiss S, Metharom P, Schmeckpeper J, Hynes B, O'Sullivan J, et al. Thrombin Stimulates Smooth Muscle Cell Differentiation From Peripheral Blood Mononuclear Cells via Protease-Activated Receptor-1, RhoA, and Myocardin. Circ Res (2009) 105:214-8. doi: 10.1161/circresaha. 109.199984

195. Albarrán-Juárez J, Kaur H, Grimm M, Offermanns S, Wettschureck N. Lineage Tracing of Cells Involved in Atherosclerosis. Atherosclerosis (2016) 251:445-53. doi: 10.1016/j.atherosclerosis.2016.06.012

196. Misra A, Feng Z, Chandran RR, Kabir I, Rotllan N, Aryal B, et al. Integrin Beta3 Regulates Clonality and Fate of Smooth Muscle-Derived Atherosclerotic Plaque Cells. Nat Commun (2018) 9:2073. doi: 10.1038/ s41467-018-04447-7

197. Wang Y, Dubland JA, Allahverdian S, Asonye E, Sahin B, Jaw JE, et al. Smooth Muscle Cells Contribute the Majority of Foam Cells in ApoE (Apolipoprotein E)-Deficient Mouse Atherosclerosis. Arterioscler Thromb Vasc Biol (2019) 39:876-87. doi: 10.1161/atvbaha.119.312434

198. Bobryshev YV. Monocyte Recruitment and Foam Cell Formation in Atherosclerosis. Micron (2006) 37:208-22. doi: 10.1016/j.micron.2005. 10.007

199. Valk FMvd, Kroon J, Potters WV, Thurlings RM, Bennink RJ, Verberne HJ, et al. In Vivo Imaging of Enhanced Leukocyte Accumulation in Atherosclerotic Lesions in Humans. J Am Coll Cardiol (2014) 64:1019-29. doi: 10.1016/j.jacc.2014.06.1171

200. Johnsen SH, Fosse E, Joakimsen O, Mathiesen EB, Stensland-Bugge E, Njølstad I, et al. Monocyte Count Is a Predictor of Novel Plaque Formation. Stroke (2005) 36:715-9. doi: 10.1161/01.str.0000158909.07634.83

201. Chapman CML, Beilby JP, McQuillan BM, Thompson PL, Hung J. Monocyte Count, But Not C-Reactive Protein or Interleukin-6, Is an Independent Risk Marker for Subclinical Carotid Atherosclerosis. Stroke (2004) 35:1619-24. doi: 10.1161/01.str.0000130857.19423.ad

202. Nasir K, Guallar E, Navas-Acien A, Criqui MH, Lima JAC. Relationship of Monocyte Count and Peripheral Arterial Disease. Arterioscler Thromb Vasc Biol (2005) 25:1966-71. doi: 10.1161/01.atv.0000175296.02550.e4

203. Kapellos TS, Bonaguro L, Gemünd I, Reusch N, Saglam A, Hinkley ER, et al. Human Monocyte Subsets and Phenotypes in Major Chronic Inflammatory Diseases. Front Immunol (2019) 10:2035. doi: 10.3389/fimmu.2019.02035

204. Villani A-C, Satija R, Reynolds G, Sarkizova S, Shekhar K, Fletcher J, et al. Single-Cell RNA-Seq Reveals New Types of Human Blood Dendritic Cells, Monocytes, and Progenitors. Science (2017) 356:eaah4573. doi: 10.1126/ science.aah 4573

205. Hamers AAJ, Dinh HQ, Thomas GD, Marcovecchio P, Blatchley A, Nakao CS, et al. Human Monocyte Heterogeneity as Revealed by High-Dimensional Mass Cytometry. Arterioscler Thromb Vasc Biol (2019) 39:25-36. doi: 10.1161/atvbaha.118.311022

206. Roussel M, Ferrell PB, Greenplate AR, Lhomme F, Gallou SL, Diggins KE, et al. Mass Cytometry Deep Phenotyping of Human Mononuclear Phagocytes and Myeloid-Derived Suppressor Cells From Human Blood and Bone Marrow. J Leukoc Biol (2017) 102:437-47. doi: 10.1189/ jlb.5ma1116-457r 
207. Fernandez DM, Rahman AH, Fernandez NF, Chudnovskiy A, Amir E-AD, Amadori L, et al. Single-Cell Immune Landscape of Human Atherosclerotic Plaques. Nat Med (2019) 25:1576-88. doi: 10.1038/s41591-019-0590-4

208. Weber C, Belge K, Hundelshausen P, Draude G, Steppich B, Mack M, et al. Differential Chemokine Receptor Expression and Function in Human Monocyte Subpopulations. J Leukoc Biol (2000) 67:699-704. doi: 10.1002/ jlb.67.5.699

209. Ancuta P, Rao R, Moses A, Mehle A, Shaw SK, Luscinskas FW, et al. Fractalkine Preferentially Mediates Arrest and Migration of CD16+ Monocytes. J Exp Med (2003) 197:1701-7. doi: 10.1084/jem.20022156

210. Wong KL, Tai JJ-Y, Wong W-C, Han H, Sem X, Yeap W-H, et al. Gene Expression Profiling Reveals the Defining Features of the Classical, Intermediate, and Nonclassical Human Monocyte Subsets. Blood (2011) 118:e16-31. doi: 10.1182/blood-2010-12-326355

211. Sander J, Schmidt SV, Cirovic B, McGovern N, Papantonopoulou O, Hardt A-L, et al. Cellular Differentiation of Human Monocytes Is Regulated by Time-Dependent Interleukin-4 Signaling and the Transcriptional Regulator Ncor2. Immunity (2017) 47:1051-66.e12. doi: 10.1016/j.immuni.2017.11.024

212. Berg KE, Ljungcrantz I, Andersson L, Bryngelsson C, Hedblad B, Fredrikson GN, et al. Elevated CD14++CD16-Monocytes Predict Cardiovascular Events. Circ Cardiovasc Genet (2012) 5:122-31. doi: 10.1161/circgenetics. 111.960385

213. Rogacev KS, Cremers B, Zawada AM, Seiler S, Binder N, Ege P, et al. CD14+ +CD16+ Monocytes Independently Predict Cardiovascular Events. J Am Coll Cardiol (2012) 60:1512-20. doi: 10.1016/j.jacc.2012.07.019

214. Meeuwsen JAL, Vries JJ de, Duijvenvoorde Av, Velden Svd, Laan SWvd, Koeverden IDv, et al. Circulating CD14+CD16-Classical Monocytes do Not Associate With a Vulnerable Plaque Phenotype, and Do Not Predict Secondary Events in Severe Atherosclerotic Patients. J Mol Cell Cardiol (2019) 127:260-9. doi: 10.1016/j.yjmcc.2019.01.002

215. Rekhter MD, Gordon D. Active Proliferation of Different Cell Types, Including Lymphocytes, in Human Atherosclerotic Plaques. Am J Pathol (1995) 147:668-77.

216. Katsuda S, Boyd HC, Fligner C, Ross R, Gown AM. Human Atherosclerosis. III. Immunocytochemical Analysis of the Cell Composition of Lesions of Young Adults. Am J Pathol (1992) 140:907-14.

217. Gordon D, Reidy MA, Benditt EP, Schwartz SM. Cell Proliferation in Human Coronary Arteries. Proc Natl Acad Sci USA (1990) 87:4600-4. doi: 10.1073/ pnas.87.12.4600
218. Lutgens E, Muinck ED de, Kitslaar PJEHM, Tordoir JHM, Wellens HJJ, Daemen MJAP. Biphasic Pattern of Cell Turnover Characterizes the Progression From Fatty Streaks to Ruptured Human Atherosclerotic Plaques. Cardiovasc Res (1999) 41:473-9. doi: 10.1016/s0008-6363(98)00311-3

219. Chai JT, Ruparelia N, Goel A, Kyriakou T, Biasiolli L, Edgar L, et al. Differential Gene Expression in Macrophages From Human Atherosclerotic Plaques Shows Convergence on Pathways Implicated by Genome-Wide Association Study Risk Variants. Arterioscler Thromb Vasc Biol (2018) 38:1. doi: 10.1161/atvbaha.118.311209

220. Vickovic S, Eraslan G, Salmén F, Klughammer J, Stenbeck L, Schapiro D, et al. High-Definition Spatial Transcriptomics for in Situ Tissue Profiling. Nat Methods (2019) 16:987-90. doi: 10.1038/s41592-019-0548-y

221. Chen H-R, Sun Y-Y, Chen C-W, Kuo Y-M, Kuan IS, Li Z-RT, et al. Fate Mapping via CCR2-CreER Mice Reveals Monocyte-to-Microglia Transition in Development and Neonatal Stroke. Sci Adv (2020) 6:eabb2119. doi: 10.1126/sciadv.abb2119

222. Heung LJ, Hohl TM. Inflammatory Monocytes Are Detrimental to the Host Immune Response During Acute Infection With Cryptococcus Neoformans. PLoS Pathog (2019) 15:e1007627. doi: 10.1371/journal.ppat.1007627

223. Xu Z, Rao Y, Huang Y, Zhou T, Feng R, Xiong S, et al. Efficient Strategies for Microglia Replacement in the Central Nervous System. Cell Rep (2020) 32:108041. doi: 10.1016/j.celrep.2020.108041

Conflict of Interest: The authors declare that the research was conducted in the absence of any commercial or financial relationships that could be construed as a potential conflict of interest.

Publisher's Note: All claims expressed in this article are solely those of the authors and do not necessarily represent those of their affiliated organizations, or those of the publisher, the editors and the reviewers. Any product that may be evaluated in this article, or claim that may be made by its manufacturer, is not guaranteed or endorsed by the publisher.

Copyright (c) 2021 Tomas, Prica and Schulz. This is an open-access article distributed under the terms of the Creative Commons Attribution License (CC BY). The use, distribution or reproduction in other forums is permitted, provided the original author(s) and the copyright owner(s) are credited and that the original publication in this journal is cited, in accordance with accepted academic practice. No use, distribution or reproduction is permitted which does not comply with these terms. 